\title{
Genome-wide local ancestries discriminate homoploid hybrid speciation from secondary introgression in the red wolf (Canidae: Canis rufus)
}

\author{
Tyler K. Chafin ${ }^{1}$ \\ Marlis R. Douglas ${ }^{1}$ \\ Michael E. Douglas ${ }^{1}$
}

${ }^{1}$ Department of Biological Sciences, University of Arkansas, Fayetteville, Arkansas 72701, USA; Email: (TKC) tkchafin@uark.edu, send reprint requests to this address; (MRD) mrd1@uark.edu; (MED) med1@uark.edu.

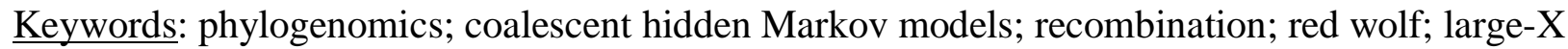
effect; hybridization

Disclosure statement: Authors have nothing to disclose. 


\section{$1 \quad$ Abstract (237)}

3 Hybridization is well recognized as a driver of speciation, yet it often remains difficult to parse

4 phylogenomically in that post-speciation gene flow frequently supersedes an ancestral signal.

5 Here we examined how interactions between recombination and gene flow shaped the

6 phylogenomic landscape of red wolf to create non-random retention of introgressed ancestry.

7 Our re-analyses of genomic data recapitulate fossil evidence by demonstrating red wolf was

8 indeed extant and isolated prior to more recent admixture with other North American canids. Its

9 more ancient divergence, now sequestered within low-recombinant regions on the X-

10 chromosome (i.e., chromosomal 'refugia'), is effectively masked by multiple, successive waves

11 of secondary introgression that now dominate its autosomal ancestry. These interpretations are

12 congruent with more theoretical explanations that describe the manner by which introgression

13 can be localized within the genome through recombination and selection. They also tacitly

14 support the large-X effect, i.e., the manner by which loci that contribute to reproductive isolation

15 can be enriched on the X-chromosome. By contrast, similar, high recombinant regions were also

16 found as enriched within very shallow gene trees, thus reflecting post-speciation gene flow and a

17 compression of divergence estimates to $1 / 20^{\text {th }}$ of that found in recombination 'cold spots'. Our

18 results effectively reconcile conflicting hypotheses regarding the impact of hybridization on

19 evolution of North American canids and support an emerging framework within which the

20 analysis of a phylogenomic landscape structured by recombination can be used to successfully

21 address the macroevolutionary implications of hybridization. 


\section{Introduction (941)}

Hybridization was once considered a rare event. However, its adaptive potential as a

28 macroevolutionary process (i.e., an unfettered access to an extensive panoply of genetic

29 variation; Grant and Grant 2019) has been enhanced by the widespread adoption of genomic

30 approaches (Abbott et al. 2013; Twyford and Ennos 2012; Taylor and Larson 2019). As such,

31 hybridization has now become one component of a more contemporary approach to species

32 diversification. Prior to the onset of genomics, there were few examples of homoploid hybrid

33 speciation in animals (Mavarez and Linares 2008), with notable exceptions being the Virgin

34 River chub (Gila seminuda; DeMarais et al. 1992; Chafin et al. 2019) and the red wolf (Canis

35 rufus; Wayne and Jenks 1991; Reich et al. 1999). Being that hybrid speciation is now becoming

36 a common hypothesis (Yakimowski and Rieseberg 2014; Elgvin et al. 2017; Lamichhaney et al.

37 2018; Eberlein et al. 2019; Marques et al. 2019), we argue that a framework must now be

38 developed so as to discriminate among its alternative outcomes [e.g. a more explicit definition of

39 'homoploid hybrid speciation;' (Schumer et al. 2014; Nieto Feliner et al. 2017; Schumer et al.

40 2018)].

41 Given the inherent difficulties associated with diagnosing hybrid speciation as the basis

42 of reproductive isolation, it has often been defined on the basis of genomic mosaicism

43 (Blanckaert and Bank 2018; Schumer et al. 2018a). However, doing so risks overlooking a more

44 varied evolutionary role for hybridization. A contributory aspect is the recognized difficulty in

45 detecting hybridization, for it is but one of several mechanisms driving phylogenetic discordance

46 in the genome (Maddison 1997; Degnan and Rosenberg 2009). Hybridization-speciation

47 dynamics are further complicated by the fact that evidence of archaic branching (i.e. those that 
precede introgression) can be depleted, and especially so in those lineages with a history of secondary introgression. However, the parsing of genealogical histories is dependent on the interactions between recombination, genetic drift, and selection (McGaugh et al. 2012; Schumer et al. 2018). As such, branching patterns are often retained non-randomly, with reduced

52 permeability to gene flow found in those genomic areas with low recombination, where

53 introgression of deleterious alleles is restricted by an increased efficacy of linked selection

54 (Payseur and Rieseberg 2016; Runemark et al. 2018; Schumer et al. 2018).

The interaction between selection and recombination through time allows fundamental

56 predictions to be made with regard to the stability of hybrids genomes, and this may promote the

57 role that hybridization plays in a given lineage. In the generations following a hybridization

58 event, recombination creates junction-points where ancestries transition from one parental

59 genome to another (Fisher 1954). Their densities along the length of a chromosome can be used

60 to find loci relating to hybrid fitness, because selection against incompatible loci will alter the

61 breadth of correlated ancestry, depressing local recombination with proportionately larger

62 distances between junctions (Sedghifar et al. 2016; Hvala et al. 2018).

63 We thus hypothesized if signatures of archaic introgression are indeed masked by

64 secondary introgression, then the probability of observing the 'original' ancestry will increase as

65 local recombination rates decrease [even when hybrid ancestries dominate, as is sometimes the

66 case (Fontaine et al. 2015)]. Thus, our prediction is that patterns of coalescence will be

67 multimodal, reflecting the times and manner by which populations have diverged and

68 subsequently intermingled (Rosenberg and Feldman 2002). Here we explore how this

69 distribution in the red wolf is shaped by genome structure and recombination rate heterogeneity. 
70 To do so, we test multiple opposing hypotheses regarding the role hybridization has played in the

71 history of this species.

73 The red wolf as a case study

Our capacity to more precisely delineate hybridization has precipitated ancillary issues,

75 such as the disparity that now exists between evolutionary complexity and species conservation

76 (Ellstrand et al. 2010; Fitzpatrick et al. 2015; Supple and Shapiro 2018; vonHoldt et al. 2018).

77 The U.S. Endangered Species Act (ESA 1973; 16 U.S.C. § 1531 et seq), as well as similar

78 legislations globally, do not protect hybrids (Jackiw et al. 2015), despite scientific support

79 (O’Brien and Mayr 1991; Allendorf et al. 2001; Haig and Allendorf 2006; Lind-Riehl et al.

80 2016). Few species have been as integral to this debate as red wolf (Canis rufus), fueled in part

81 by the long-standing ambiguity surrounding its origins (Gittleman and Pimm 1991; Wayne and

82 Jenks 1991; Dowling et al. 1992; Nowak 1992).

83 DNA evidence implicates hybridization, which some have attributed to recent coyote $(C$.

84 latrans) and grey wolf (C. lupus) admixture (Wayne and Jenks 1991; Roy et al. 1996; Reich et

85 al. 1999; vonHoldt et al. 2011; vonHoldt et al. 2016). Alternatively, others have instead argued

86 that data point to an earlier red wolf origin, with introgression occurring as a subsequent

87 phenomenon (Nowak 1979; Dowling et al. 1992; Nowak 1992; Wilson et al. 2000; Nowak 2002;

88 Hohenlohe et al. 2017). Hypotheses regarding the status of red wolf are as follows (per Waples et

89 al. 2018). It is: (1) An evolutionary distinct lineage derived from common ancestry with either $C$.

90 lupus or C. latrans (=secondary introgression); (2) A transient product produced by

91 contemporary hybridization (=hybrid swarm), or (3) An admixture subsidiary to a more ancient

92 hybridization (=hybrid speciation). We discriminate among these scenarios by establishing 
93 predictions with regard to the respective footprint each would leave on the genomic landscape of

94 red wolf, then testing each to ascertain which has the greatest probability of occurrence.

96 Results (1459)

99 North American gray wolf (C. lupus) and coyote (C. latrans)], as well as an outgroup species

100 (red fox; Vulpes vulpes). We aligned these data against the domestic dog genome (Kirkness et al.

101 2003; Lindblad-Toh et al. 2005; Hoeppner et al. 2014), then extracted full chromosome-length

102 'pseudoalignments' from all nucleotide positions having sufficient sequencing depth. This

103 resulted in an average of $95.5 \%$ of the genome having called bases across species.

To identify sub-genomic ancestry blocks, we partitioned the 38 autosomes and the $\mathrm{X}$

105 chromosome into 913,849 non-overlapping windows by using an algorithm that defined a 'most

106 parsimonious' set of hypothesized ancestry breakpoints, given a four-gamete assumption (Chafin

107 2020). This provided data with an average length of $2.2 \mathrm{~kb}(10.3 \mathrm{~kb}$ if merging consecutive

108 ancestry blocks; see Fig. S1). We then analyzed each chromosome separately, and additionally

109 partitioned regions by recombination rate, as inferred using an existing high-density linkage map

110 (Fig. S2)(Wong and Neff 2009; Wong et al. 2010).

111 Our analyses are presented in two stages: The first examines the distribution of

112 phylogenies across the genome. Here, we reasoned that sub-genomes from the putative parental

113 lineages could be assigned via Maximum Likelihood (ML) estimates of the local branching

114 order. We then identified heterozygous ancestry blocks by calculating the interspecific

115 heterozygosity of red wolf sequence within each sub-alignment. We established relatively simple 116 predictions for these early analyses: If indeed hybridization is recent (per Wayne and Jenks 1991; 
117 vonHoldt et al. 2016), then ancestry blocks will be large, given scant time for linkage blocks to

118 be broken up by recombination (Falush et al. 2003; Pool and Nielsen 2009)]. Also, interspecific

119 heterozygosity should be high (Rieseberg and Linder 1999; Anderson and Thompson 2002),

120 whereas raw divergence will be low (vonHoldt et al. 2017). Likewise, we also expect an

121 enrichment of introgressed histories in regions with higher recombination (Schumer et al. 2018;

122 Li et al. 2019). We then used a model of linkage block decay to test several alternative models of

123 hybridization, with gene flow either being gradual (e.g. declining through time from an initial

124 event), continuous, or have occurred in multiple independent waves (Ni et al. 2018). However,

125 when gene flow is high, signals of more ancient divergence could be 'masked.'

126 To untangle this, our second approach employed local phylogenetic signals as latent

127 variables within a hidden Markov model [=coalHMMs (Dutheil et al. 2009; Spence et al. 2018)].

128 It allowed us to extract parameter estimates (e.g. divergence times) by integrating results from

129 coalescent theory, despite the fact that the 'true' history at each nucleotide is masked (Hobolth et

130 al. 2007; Dutheil et al. 2009). We then contrasted this approach with a second coalescent-based

131 method [g-PhoCS; (Gronau et al. 2011)] that replicates the analyses of vonHoldt et al. (2016)

132 with the exception that inputs were additionally partitioned by their respective sub-genomic

133 histories.

Phylogenetic estimation and interspecific heterozygosity revealed that $26.8-36.5 \%$ of

137 ancestral blocks were heterozygous (Fig. S3), with per-base gray wolf ancestry representing

$138 \quad 23.2-41.7 \%$ (depending on measurement; Table S1). These results are congruent with previous

139 studies that estimated 20-25\% from SNP data (vonHoldt et al. 2011), and 17-33\% using 
140 microsatellite data (Roy et al. 1994; Bertorelle and Excoffier 1998). Of note, an anomalous

141 sister-relationship of red wolf to red fox (as outgroup) was supported by $17.9 \%$ of the data, a

142 likely result of direct introgression between coyote and gray wolf (Lehman et al. 1991;

143 Gopalakrishnan et al. 2018; Pilot et al. 2019), and/ or inflated discordance due to bottlenecks in 144 contemporary red wolf populations (Brzeski et al. 2014; Waples et al. 2018). Divergence from

145 source genomes was remarkably low, with homozygous ancestry blocks across all chromosomes 146 with $\mathrm{D}_{\mathrm{XY}}=0$ identified as $49.3 \%$ coyote and $54.5 \%$ gray wolf.

The distribution of ancestries was notably non-random (Fig. S4-S5), with a substantial

148 enrichment of coyote ancestry on the X-chromosome (Fig. 1A). This was most pronounced in

149 regions of low recombination $(<0.5 \mathrm{cM} / \mathrm{Mb})$. It thus comes as no surprise that a significantly

150 higher mean recombination rate was found when gray wolf ancestry blocks were compared

151 between autosomes and X-chromosome (where it is enriched at higher recombination rates;

152 Table 1).

154 Testing the hybrid origin hypothesis

155 Given the observed distribution of recombination-structured ancestries, two questions

156 emerge with regard to hybridization: (1) Did the temporal context of hybridization contribute to

157 the non-random representation of ancestries? (2) Did hybridization occur as a 'homoploid hybrid

158 speciation' event? or (3) Did admixture occur subsequent to a pre-existing isolation? To address

159 these questions, we developed several predictions as a test mechanism in the context of a

160 discriminative framework.

161 We first recognized the positive relationship between the efficacy of linked selection and 162 the size of linkage blocks in the genome (Nachman and Payseur 2012). Given this, should there 
163 be signatures of isolation that pre-date admixture? If so, they would then be expected to occur

164 with highest probability in those regions with low recombination. Likewise, introgressed

165 ancestries are more probable within high-recombination regions where deleterious alleles can be

166 more readily decoupled from neutral or beneficial surroundings (Schumer et al. 2018).

167 We found positive results in the non-random distribution of ancestries, where a more

168 pronounced occurrence of enriched coyote ancestry was seen within low-recombination regions

169 of the X-chromosome. To expand on this, we also predicted if introgression does indeed mask

170 prior isolation, then those affected genomic regions would display a more shallow coalescence

171 with respect to divergence events (Rosenberg and Feldman 2002; Leache et al. 2014).

172 Juxtaposition of these predictions allowed us to test the hypothesis of hybrid origin versus

173 secondary admixture: If older divergences predominate in areas of low recombination, then the

174 'original' branching pattern is retained (e.g. Fontaine et al. 2015). By partitioning divergence

175 according to recombination rate, we can then unmask ancestral divergence previously obscured.

176 We fitted a coalescent hidden Markov model (coalHMM) implementing admixture

177 (Cheng and Mailund 2020) to $1 \mathrm{Mb}$ blocks of the red wolf genome. We did so to obtain local

178 estimates for red wolf divergence times with regard to coyote $\left(\tau_{\mathrm{COY}}\right)$ and gray wolf $\left(\tau_{\mathrm{WOLF}}\right)$

179 progenitors, as well as putative estimates of post-gene flow isolation $\left(\tau_{\mathrm{H}}\right)$. In so doing, we

180 uncovered a marked disparity in the range of these estimates between autosomes and the X-

181 chromosome (Fig. 1B and S6-S8). The autosomal estimates were reasonably homogenous across

182 recombination rate bins. This was not so on the X-chromosome: While $\tau_{\mathrm{WOLF}}$ and $\tau_{\mathrm{H}}$ were

183 relatively consistent among recombination rate bins, $\tau_{\mathrm{COY}}$ suggested 20 -times older divergence in

184 regions where $\mathrm{cM} / \mathrm{Mb}<0.5$ than in regions where $\mathrm{cM} / \mathrm{Mb}>2.0(\mu=0.004$ versus $\mu=0.0002)$.

185 Thus, divergence was found to be substantially higher in low-recombination regions of the X- 
chromosome, with younger branching times instead dominating high-recombination regions and

187 the autosomal genome.

We then sampled $\sim 6000$ putatively neutral regions from each parental red wolf sub-

189 genome (following Freedman et al. 2014; vonHoldt et al. 2016) as a means of applying the same

190 demographic modelling approach used in previous studies (i.e. g-PhoCS; Gronau et al. 2011).

191 Results indicated much younger age estimates than those from the COALHMM approach (Fig. 2

192 and S9), with a mean posterior mutation-scaled divergence time $\tau_{\mathrm{COY}}=3.8 \times 10^{-5}$ and

$193 \tau_{\mathrm{WOLF}}=5.9 \times 10^{-6}$ (Table S2). Assuming a generation time of three years and an average per-

194 generation mutation rate of $4 \times 10^{-9}$ (vonHoldt et al. 2016), these correspond to $\sim 28,500$ and

$195 \sim 4,425$ years, respectively. These are congruent with COALHMM estimates taken from high

196 recombination regions of the X chromosome. Interestingly, these results echo a known effect

197 wherein the inclusion of introgressed gene histories promotes 'tree compression,' or an

198 underestimation of divergence times (Leache et al. 2014). We also noted several long contiguous

199 blocks showing complete loss of heterozygosity ( $\mathrm{LOH})$, in some cases stretching $>25 \mathrm{Mb}$ (Fig.

200 3). However, there was no difference in branching time estimates among LOH and non-LOH

201 segments (Fig. 3).

202 The observed multi-modality estimates in divergence time suggest multiple separate

203 exchanges between red wolf and putative progenitors (Fig. 1B and S8). To assess this, we took

204 advantage of another prediction: The expected decline in lengths of ancestry blocks over time, as

205 a product of meiotic recombination (Gravel 2012; Ni et al. 2018). Here, the distribution of

206 ancestry-tract lengths in each chromosome was best explained by either two- or three- pulse

207 admixture models (Fig. S10-S11), with the exception of chr9, chr13, and chr37 which fit more

208 appropriately with a gradual admixture model (e.g. with the rate of gene flow continually 
209 declining with time since an initial event). The timing of the most recent admixture among those

210 displaying multiple waves $(\mathrm{N}=36 / 39)$ was estimated to be within the last few hundred

211 generations. Older admixtures had a more diffuse distribution, ranging from 250-2000

212 generations (Fig. 4). Mean admixture proportions for distinct pulses ranged from 0.286-0.533 for

213 coyote, and $0.367-0.557$ for gray wolf, although the estimated variance in older events was

214 elevated (Fig. S12).

216 Discussion (1111)

217 Our findings suggest that extensive secondary introgression, as facilitated by increased

218 permeability of autosomes relative to the X-chromosome, effectively obscured the pre-existing

219 divergence of red wolf. In this sense, the autosomal genome is comparatively homogenous (Fig.

220 1A), with a low raw divergence and a systematic under-estimation of divergence times stemming

221 from the predominance of introgressed ancestry (Fig. 1B). These results provide quantitative data

222 in support of previous studies that found disproportionate retention of ancient branching patterns

223 in low-recombining regions of sex chromosomes (Fontaine et al. 2015; Schumer et al. 2018;

224 Edelman et al. 2019). This stems from a simultaneous reduction in the rate at which contiguous

225 phylogenetic histories are degraded by linkage, as well as the bolstered efficacy of selection in

226 purging deleterious introgressed elements (Nachman and Payseur 2012; Martin et al. 2019).

227 Moreover, our replication of previous studies (Fig. 2) yielded substantially younger divergence

228 estimates than those from previous studies partitioned by chromosome and recombination rate

229 (Fig. 1B). Our observations agree with prior studies in underscoring the presence of "tree

230 compression,' or a branch lengths reduced/ distorted due to an inability to partition introgressed

231 fron non-introgressed ancestries (Leache et al. 2014; Bangs et al. 2018). 
233 phenomenon found in those taxa exhibiting XY and ZW sex determination systems (Fontaine et

234 al. 2015; Seixas et al. 2018; Martin et al. 2019). It is consistent with a 'large-X effect' that

235 predicts loci contributing to reproductive isolation accumulate disproportionately on the X- (or

236 Z-) chromosome (Coyne and Orr 1989; Van Belleghem et al. 2018; Presgraves 2018; Runemark

237 et al. 2018). Our results also demonstrated an enrichment of coyote ancestry in low-

238 recombination regions of the X-chromosome, whereas shallower divergence was found within

239 high-recombination regions. A similar logic was presented in Fontaine et al. (2015), wherein a

240 phylogenomic study of Anopholes mosquitos also revealed extensive conflict between autosomes

241 and the X-chromosome in the locally dominant branching pattern. They reasoned that gene trees

242 whose branching patterns reflect that of speciation rather than secondary introgression should

243 exhibit deeper coalescence (Fontaine et al. 2015). Such a scenario would similarly explain the

244 patterns of divergence observed in red wolf. Thus, we posit that while masked by secondary

245 introgression in the majority of the genome, lower X-permeability acts as a barrier to exchange,

246 effectively preserving those coalescent patterns established during a more ancient divergence of

247 the red wolf with a coyote-like ancestor.

249 Reconciling conflict among genetic and morphological hypotheses

250 Previous analyses employing these data sparked considerable disagreement, primarily

251 with regards to the timing of gene flow (vonHoldt et al. 2016; Hohenlohe et al. 2017; vonHoldt

252 et al. 2017). The discrepancy between our results and prior studies is two-fold, and stems from:

253 A failure to consider sequential coalescent signal (e.g. as in COALHMM), and the nature of local

254 ancestries structured throughout the genome. Our results are most consistent with an older 
divergence between coyote and red wolf, an occurrence long obscured by multiple pulses of 256 contemporary admixture (Fig. 4 and S11).

We interpret our results as reconciling the conflict between inferences based on recent

258 molecular work, and those stemming from analyses of modern and historical skeletal remains

259 (e.g. Nowak, 1992). Indeed, the genome does indeed harbor signals of recent and ancient

260 divergences, as established from multiple waves of admixture that successively degraded archaic

261 branching patterns. The most recent admixture event is potentially associated with contemporary

262 anthropogenic change. In this sense, morphological studies could not demonstrate hybridization

263 until the early 1900s, when specimens began trending towards coyote morphologies (Nowak

264 1979; Nowak 1992; Nowak 2002).

265 One prevailing question is the status of red wolf prior to modern admixture. Our data

266 suggests its earlier origin, although an absolute estimate is difficult to establish in that effective

267 population sizes, mutation rates, and generation times are all indeterminate (Hohenlohe et al.

268 2017). Haplotype block lengths suggest admixture as old as 1500-2000 generations (Fig. 4),

269 which would place an upper bound extending into the early Holocene, depending on how

270 generation time is defined. Fossil evidence suggests an ecological niche shift in coyote

271 corresponding to megafaunal extinctions at the Pleistocene-Holocene boundary (Meachen and

272 Samuels 2012). Individual body size during the transition period were intermediate between

273 large Pleistocene individuals and more contemporary counterparts that were comparatively

274 diminutive (Meachen et al. 2014). Response of canids to dietary shifts, demographic instability at

275 the glacial-interglacial interface, and wide-spread shuffling of distributions (Pardi and Smith

276 2016; Loog et al. 2019) may have promoted interspecific contact. We suggest this scenario has

277 plausibility, given the emerging adaptive role for hybridization now commonly evoked in diverse 
taxa (Lewontin and Birch 2006; Meier et al. 2017; Jones et al. 2018), to include canids (Kays et

al. 2010; vonHoldt et al. 2016).

\section{Conclusion}

We employed a fine-scaled, partitioned analysis of genome-wide phylogenetic patterns in

282 red wolf to show that branching patterns reflecting secondary introgression dominate. We also

283 discovered that the presence of introgression varies throughout the genome, as a product of

284 genomic context (e.g. local recombination rates). Because of this, evidence of older divergence

285 was retained by only a fraction of the historically reduced recombination. These findings

286 highlight the difficulties in studying the prevalence of hybridization within the broader Tree of

287 Life, where a sufficiently large numbers of loci can presumably render a singular species history

288 as transparent (Philippe et al. 2011; Hahn and Nakhleh 2016).

However, two biases hinder this approach: (1) The magnitude of signal among loci is

290 clearly disproportionate (Arcila et al. 2017; Shen et al. 2017); and (2) signatures in the genome

291 are deposited by different processes in a heterogeneous manner (as herein). Methods to correct

292 for these biases must explicitly consider the rate of recombination that effectively drives this

293 discrepancy (Payseur and Rieseberg 2016). A failure to do so with regard to red wolf yielded

294 divergence estimates orders of magnitude less than those suggested by fossil evidence (Nowak

295 1992; Nowak 2002). We reconciled this discrepancy herein by employing estimates based solely

296 on low recombinant regions of the X chromosome. Given this, a failure to partition distinct

297 coalescent histories (e.g. Springer and Gatesy 2018) may result in some phylogenomic studies

298 being interpreted as an artefact of substantial branch length distortion (Leache et al. 2014). The

299 solution is to reconsider the non-random manner by which phylogenetic signal is retained in the

300 genome. This was possible in our red wolf study due to the presence of substantial a priori data, 
301 to include chromosomal reference assemblies and high-density linkage maps. There are two

302 stumbling blocks to the widespread application of this approach: Resource-limitations and

303 methodological-deficiencies. Both are crucially important if we are to develop a more mature

304 theory of hybridization as a macroevolution process (per Folk et al. 2018).

Methods (1345)

Read processing, quality filtering, and genotyping

309 American gray wolf (=GW; Canis lupus), and coyote (=COY; Canis latrans), with the red fox

310 (=VUL; Vulpes vulpes) serving as an outgroup (vonHoldt et al. 2016a; Kukekova et al. 2018).

311 Paired-end reads were downloaded from the NCBI SRA (SRR7107787; SRR7107783;

312 SRR1518489; SRR5328101-115) and mapped to the domestic dog assembly (CanFam3.1) using

313 BOWTIE2 (Langmead and Salzberg 2012) with sensitive settings, and excluding discordant pairs

314 and unaligned reads. Further processing, sorting, and indexing was performed in SAMTOOLS (Li

315 et al. 2009). PCR duplicates were filtered in PICARD (Broad Institute;

316 broadinstitute.github.io/picard), followed by indel realignment and base quality recalibration in

317 GATK (McKenna et al. 2010; Van der Auwera et al. 2013) as preparation for the

318 HAPLOTYPECALLER pipeline using the 'Best Practices' workflow. Genotypes were then inferred

319 jointly using GATK GENOTYPEGVCFs, followed by post-processing, quality filtering, and

320 merging of variant and indel calls.

322 Genome-wide phylogenetic patterns 
324 full chromosomal pseudoalignments using a conservative phylogenetic approach, then built

325 pseudoalignments from variant data using a custom Python code

326 (github.com/tkchafin/vcf2msa.py). One issue with this approach is that one cannot assume the

327 genomic reference state for a given nucleotide position will be consistent across the sampled

328 genomes. Thus, within each genome, non-polymorphic bases were treated as un-callable ("N")

329 when local read depth was $<5$. A single-pass algorithm was then used to examine variants

330 (SNPs) for failure of the four-gamete condition (FGT; Hudson and Kaplan 1985). Given the

331 resulting set of incompatible intervals, we then resolved a minimum set of ancestry breakpoints

332 for which no FGT incompatibilities persisted (available as open-source; Chafin 2020).

333 Delimited blocks were then assigned ancestry using a phylogenetic method. Here, we

334 computed a maximum likelihood estimate (MLE) in IQ-TREE (Nguyen et al. 2014) using

335 integrated model selection and optimization of rate parameters. We discriminated weakly

336 supported relationships by additionally calculating likelihoods under constrained topology

337 searches for each possible quartet resolution, and testing for significant exclusion of alternatives

338 from the MLEs by calculating a bootstrap proportion computed using the RELL approximation

339 (Kishino et al. 1990). Sources of mixed support as a result of systematic errors were

340 differentiated within a given block. For example, the incorrect spanning of recombination events

341 (resulting in concatenated ancestry blocks) was separated from that due to unphased hybrid

342 diplotypes by measuring interspecific heterozygosity. This was derived as the fraction of fixed

343 nucleotide polymorphisms between coyote and gray wolves that were heterozygous for red wolf.

345 Testing for multiple-pulse and gradual admixture 
Hybrid ancestries are expected to be arranged in large contiguous blocks following an

347 admixture event, with the size of linkage blocks subsequently breaking down over time (Baird et

348 al. 2003). The distribution of ancestry tracts lengths post-admixture can thus be used to

349 understand the timings of genomic contributions (Gravel 2012; Liang and Nielsen 2014), as well

350 as to discriminate multiple-pulse versus continuous admixture models (Zhou et al. 2017; Ni et al.

$3512018)$.

352 To explicitly test among these scenarios, we built a custom SNAKEMAKE pipeline

353 (github.com/tkchafin/multiwaver_snakemake_workflow) for running MULTIWAVER_2.0 (Ni et

354 al. 2018a). To do so, we converted from physical (bp) to genetic (cM) coordinates by utilizing

355 the available comprehensive linkage map for the dog genome (Wong and Neff 2009; Wong et al.

356 2010). Because the linkage map was built for an earlier version of the assembly (CanFam2), we

357 first converted them using a Python wrapper (available as open-source at

358 github.com/tkchafin/scripts/liftoverCoords.py) for the UCSC LIFTOVER command-line utility

359 (Hinrichs et al. 2006). We then used the LIFTOVER-converted linkage map to construct Marey

360 maps (Siberchicot et al. 2017) for each chromosome, and convert junction positions using cubic

361 interpolation. Ancestries were then assigned to each block based on the phylogenetic results,

362 with blocks having interspecific heterozygosity $>0.1$ randomly haploidized. We generated 100

363 independent replicates for each chromosome so as to quantify stochastic variation caused by

364 random 'pseudo-haploid' resolution.

366 Fitting full-genome admixture histories using coalHMMs

367 We inferred divergence time parameters using an MCMC (Markov Chain Monte Carlo)

368 sampler for an admixture coalescent HMM (hidden Markov model). HMMs provide a means to 
probabilistically model transitions along serial or sequential datasets, and are employed widely in genomics and phylogenetics (gene prediction, Stanke and Waack 2003; nucleotide evolution,

371 Yang 1995; Felsenstein and Churchill 1996; and patterns of phylogenetic and geographic

372 diversification, Beaulieu and O’Meara 2016; Caetano et al. 2018). Coalescent HMMs

373 (=coalHMMs) construct a Markov model along a sequence alignment, with 'hidden' states as

374 features to reconstruct (Dutheil et al. 2009; Li and Durbin 2011). Hidden states that represent

375 genealogies or coalescent histories are themselves unobservable yet can be predicted from the

376 observed states (=sequence data). Parameters involve processes controlling transitions among

377 hidden states, such as recombination rates $(r)$, effective population sizes $\left(N_{\mathrm{e}}\right)$, and speciation

378 times $(\tau)$ (Dutheil et al. 2009). Often (as herein) the primary objective is to infer those

379 demographic parameters from which transition rates are derived (Mailund et al. 2011). In the

380 case of the admixture coalHMM (Cheng and Mailund 2015, 2020), HMMs implementing

381 isolation-with-migration models (Mailund et al. 2012) are combined to generate a

382 pseudolikelihood (or 'composite' likelihood) of more complex models that involve multiple

383 lineages. Here we specified priors for the MCMC optimization using demographic estimates

384 from vonHoldt et al. (2016).

385 Due to the computational complexity of the coalHMM approach (Cheng and Mailund

$3862015,2020)$, the analysis was run separately in 1-million base blocks in two independent

387 replicates per block. We then determined optimal burn-in values using an iterative approach

388 (removing 5\% of samples per iteration) using the Geweke diagnostic (Geweke 1992). We also

389 computed effective sample sizes (ESS) for all parameters and assessed convergence of

390 independent chains using the Gelman-Rubin convergence test (Gelman and Rubin 1992; Brooks 
and Gelman 1998) in the R package CODA (Plummer et al. 2006), removing any blocks for which any parameter-wise ESS fell below 100 or having a Gelman-Rubin statistic $<1.01$.

\section{Coalescent demographic modeling}

397 PHoCS; Gronau et al. 2011). We first excluded regions within a 10kb flanking distance of coding genes (Hoeppner et al. 2014), or conserved non-coding elements (CNEs). The latter were annotated using PHASTCONS scores (Siepel et al. 2005) provided for the Euarchontoglires clade, as mapped to the mouse genome (mm9) on UCSC (Freedman et al. 2014). CNEs were then

401 defined as contiguous (over 50bp in length) PHASTCONS scores >0.7 (per Freedman et al. 2014).

402 Interval coordinates for both CNEs and coding genes were converted to the CANFAM3.1

403 coordinate system (Hinrichs et al. 2006). Our filtered VCF, with reference genome and BED file

404 defining excluded regions, were input to a generalized pipeline (Chafin et al. 2018) that allows

405 for discovery of targeted sub-alignments in genomic datasets. Additional constraints targeted

406 sub-alignments with a maximum proportion of 0.5 uncalled $(\mathrm{N})$ or gap bases. We then subtracted

407 regions from this which were identified as having heterozygous ancestry, and further sampled

408 regions which were at least $100 \mathrm{~kb}$ apart, truncating regions greater than $5 \mathrm{~kb}$ in length. Resulting

409 intervals were then extracted as full pseudo-alignments using custom Python code

410 (github.com/tkchafin/vcf2msa.py), with an additional constraint that invariant bases for each

411 species retain the reference base only where $>5$ reads present; lower-coverage bases were treated

412 as un-callable ("N"). These were then divided into 'sub-genomes' by querying dominant

413 phylogenetic ancestry assignments, removing alignments shorter than 500bp, resulting in

$414 \mathrm{~N}=6,100$ and 6,255 for gray wolf and coyote sub-genomes ( $\mathrm{N}=12225$ loci in total). These served 
415 as input for demographic inference in G-PHOCS following the same protocol used in prior studies

416 (Freedman et al. 2014; vonHoldt et al. 2016a).

\section{Acknowledgements}

420 We thank vonHoldt et al. and Kukekova et al. for making their data available via the NCBI

421 public repository. We are also indebted to students, postdoctorals, and faculty who have

422 contributed thoughtful discussion, assistance with computational resources, or otherwise

423 promoted this work: A. Alverson, M. Bangs, J. Boyko, D. Caetano, D. Chaffin, T. Dowling, J.

424 Pummil, B. Martin, S. Mussmann, A. Tucker, P. Wolinski, and Z. Zbinden. Funding was

425 provided by several generous endowments from the University of Arkansas: The Bruker

426 Professorship in Life Sciences (MRD), and the Twenty-First Century Chair in Global Change

427 Biology (MED). Additional analytical resources were provided by the Arkansas Economic

428 Development Commission (Arkansas Settlement Proceeds Act of 2000) and the Arkansas High

429 Performance Computing Center (AHPCC), and from an NSF-XSEDE Research Allocation (TG-

430 BIO160065) to access the JetStream cloud.

432 Data availability

433 All data for this work were taken from public repositories. Source codes developed in support of 434 this work are available publicly on GitHub (github.com/tkchafin and as cited in-text). 


\section{References}

Abbott R., Albach D., Ansell S., Arntzen J.W., Baird S.J.E., Bierne N., Boughman J., Brelsford A., Buerkle C.A., Buggs R., Butlin R.K., Dieckmann U., Eroukhmanoff F., Grill A., Cahan S.H., Hermansen J.S., Hewitt G., Hudson A.G., Jiggins C., Jones J., Keller B., Marczewski T., Mallet J., Martinez-Rodriguez P., Möst M., Mullen S., Nichols R., Nolte A.W., Parisod C., Pfennig K., Rice A.M., Ritchie M.G., Seifert B., Smadja C.M., Stelkens R., Szymura J.M., Väinölä R., Wolf J.B.W., Zinner D. 2013. Hybridization and speciation. J. Evol. Biol. 26:229-246.

Allendorf F.W., Leary R.F., Spruell P., Wenburg J.K. 2001. The problems with hybrids: Setting conservation guidelines. Trends Ecol. Evol. 16:613-622.

Anderson E.C., Thompson E. a. 2002. A model-based method for identifying species hybrids using multilocus data. Genetics. 160:1217-1229.

Arcila D., Ortí G., Vari R., Armbruster J.W., Stiassny M.L.J., Ko K.D., Sabaj M.H., Lundberg J., Revell L.J., Betancur-R. R. 2017. Genome-wide interrogation advances resolution of recalcitrant groups in the tree of life. Nat. Ecol. Evol. 1:1-10.

Van der Auwera G.A., Carneiro M.O., Hartl C., Poplin R., del Angel G., Levy-Moonshine A., Jordan T., Shakir K., Roazen D., Thibault J., Banks E., Garimella K. V., Altshuler D., Gabriel S., DePristo M.A. 2013. From FastQ data to high-confidence variant calls: The genome analysis toolkit best practices pipeline. Curr. Protoc. Bioinforma. 43:11-10.

Baird S.J.E., Barton N.H., Etheridge A.M. 2003. The distribution of surviving blocks of an ancestral genome. Theor. Popul. Biol. 64:451-471.

Bangs M.R., Douglas M.R.M.E., Mussmann S.M., Douglas M.R.M.E. 2018. Unraveling historical introgression and resolving phylogenetic discord within Catostomus (Osteichthys $\square$ : Catostomidae). BMC Evol. Biol. 18:86.

Beaulieu J.M., O’Meara B.C. 2016. Detecting hidden diversification shifts in models of traitdependent speciation and extinction. Syst. Biol. 65:583-601.

Van Belleghem S.M., Baquero M., Papa R., Salazar C., McMillan W.O., Counterman B.A., Jiggins C.D., Martin S.H. 2018. Patterns of Z chromosome divergence among Heliconius species highlight the importance of historical demography. Mol. Ecol. 27:3852-3872.

Bertorelle G., Excoffier L. 1998. Inferring admixture proportions from molecular data. Mol. Biol. Evol. 15:1298-1311.

Blanckaert A., Bank C. 2018. In search of the Goldilocks zone for hybrid speciation. PLoS Genet. 14:1-23.

Brooks S.P., Gelman A. 1998. General methods for monitoring convergence of iterative simulations. J. Comput. Graph. Stat. 7:434-455. 
Brzeski K.E., Rabon D.R., Chamberlain M.J., Waits L.P., Taylor S.S. 2014. Inbreeding and inbreeding depression in endangered red wolves (Canis rufus). Mol. Ecol. 23:4241-4255.

Caetano D.S., O’Meara B.C., Beaulieu J.M. 2018. Hidden state models improve state-dependent diversification approaches, including biogeographical models. Evolution. 72:2308-2324.

Chafin T.K. 2020. FGTpartitioner $\square$ : A rapid method for parsimonious delimitation of ancestry breakpoints in large genome-wide SNP datasets. J. Open Source Softw. 5:2030.

Chafin T.K., Douglas M.R., Bangs M.R., Mussmann S.M., Douglas M.E. 2019. Taxonomic Uncertainty and Phylogenomics: Rescuing a Contentious Species Complex from the Anomaly Zone. bioRxiv. 692509.

Chafin T.K., Douglas M.R., Douglas M.E. 2018. MrBait: universal identification and design of targeted-enrichment capture probes. Bioinformatics. 34:4293-4296.

Cheng J.Y., Mailund T. 2015. Ancestral population genomics using coalescence hidden Markov models and heuristic optimisation algorithms. Comput. Biol. Chem. 57:80-92.

Cheng J.Y., Mailund T. 2020. Ancestral Population Genomics with Jocx, a Coalescent Hidden Markov Model. In: Dutheil J.Y., editor. Statistical Population Genomics, Methods in Molecular Biology vol. 2090. New York: Springer Protocols. p. 167-189.

Coyne J.A., Orr H.A. 1989. Patterns of speciation in Drosophila. Evolution. 43:362-381.

Degnan J.H., Rosenberg N.A. 2009. Gene tree discordance, phylogenetic inference and the multispecies coalescent. Trends Ecol. Evol. 24:332-340.

DeMarais B.D., Dowling T.E., Douglas M.E., Minckley W.L., Marsh P.C. 1992. Origin of Gila seminuda (Teleostei: Cyprinidae) through introgressive hybridization: implications for evolution and conservation. Proc. Natl. Acad. Sci. U. S. A. 89:2747-2751.

Dowling T.E., DeMarais B.D., Minckley W.L., Douglas M.E., Marsh P.C. 1992. Use of genetic characters in conservation biology. Conserv. Biol. 6:7-8.

Dutheil J.Y., Ganapathy G., Hobolth A., Mailund T., Uyenoyama M.K., Schierup M.H. 2009. Ancestral population genomics: The coalescent hidden Markov model approach. Genetics. 183:259-274.

Eberlein C., Hénault M., Fijarczyk A., Charron G., Bouvier M., Kohn L.M., Anderson J.B., Landry C.R. 2019. Hybridization is a recurrent evolutionary stimulus in wild yeast speciation. Nat. Commun. 10:923.

Edelman N.B., Frandsen P.B., Miyagi M., Clavijo B., Davey J., Dikow R.B., García-accinelli G., Belleghem S.M. Van, Patterson N. 2019. Genomic architecture of introgression shape a butterfly radiation. Science. 599:594-599.

Elgvin T.O., Trier C.N., Tørresen O.K., Hagen I.J., Lien S., Nederbragt A.J., Ravinet M., Jensen 
H., Sætre G.P. 2017. The genomic mosaicism of hybrid speciation. Sci. Adv. 3:1-16.

Ellstrand N.C., Biggs D., Kaus A., Lubinsky P., McDade L.A., Preston K., Prince L.M., Regan H.M., Rorive V., Ryder O.A., Schierenbeck K.A. 2010. Got Hybridization? A Multidisciplinary Approach for Informing Science Policy. Bioscience. 60:384-388.

Falush D., Stephens M., Pritchard J.K. 2003. Inference of Population Structure Using Multilocus Genotype Data: Linked Loci and Correlated Allele Frequencies. Genetics. 164:15671587.

Felsenstein J., Churchill G.A. 1996. A Hidden Markov Model approach to variation among sites in rate of evolution. Mol. Biol. Evol. 13:93-104.

Fisher R.A. 1954. A fuller theory of “junctions” in inbreeding. Heredity. 8:187-197.

Fitzpatrick B.M., Ryan M.E., Johnson J.R., Corush J., Carter E.T. 2015. Hybridization and the species problem in conservation. Curr. Zool. 61:206-216.

Folk R.A., Soltis P.S., Soltis D.E., Guralnick R. 2018. New prospects in the detection and comparative analysis of hybridization in the tree of life. Am. J. Bot. 105:364-375.

Fontaine M.C., Pease J.B., Steele A., Waterhouse R.M., Neafsey D.E., Sharakhov I. V., Jiang X., Hall A.B., Catteruccia F., Kakani E., Mitchell S.N., Wu Y.-C., Smith H.A., Love R.R., Lawniczak M.K., Slotman M.A., Emrich S.J., Hahn M.W., Besansky N.J. 2015. Extensive introgression in a malaria vector species complex revealed by phylogenomics. Science. 347:1258524.

Freedman A.H., Gronau I., Schweizer R.M., Ortega-Del Vecchyo D., Han E., Silva P.M., Galaverni M., Fan Z., Marx P., Lorente-Galdos B., Beale H., Ramirez O., Hormozdiari F., Alkan C., Vilà C., Squire K., Geffen E., Kusak J., Boyko A.R., Parker H.G., Lee C., Tadigotla V., Siepel A., Bustamante C.D., Harkins T.T., Nelson S.F., Ostrander E.A., Marques-Bonet T., Wayne R.K., Novembre J. 2014. Genome sequencing highlights the dynamic early history of dogs. PLoS Genet. 10:e1004016.

Gelman A., Rubin D.B. 1992. Inference from iterative simulation using multiple sequences. Stat. Sci. 7:457-472.

Geweke J. 1992. Evaluating the accuracy of sampling-based approaches to the calculation of posterior moments. Fed. Reserv. Bank Minneapolis, Res. Dep.

Gittleman J.L., Pimm S.L. 1991. Crying wolf in North America. Nature. 351:524-525.

Gopalakrishnan S., Sinding M.H.S., Ramos-Madrigal J., Niemann J., Samaniego Castruita J.A., Vieira F.G., Carøe C., Montero M. de M., Kuderna L., Serres A., González-Basallote V.M., Liu Y.H., Wang G.D., Marques-Bonet T., Mirarab S., Fernandes C., Gaubert P., Koepfli K.P., Budd J., Rueness E.K., Heide-Jørgensen M.P., Petersen B., SicheritzPonten T., Bachmann L., Wiig Ø., Hansen A.J., Gilbert M.T.P. 2018. Interspecific gene flow shaped the evolution of the genus Canis. Curr. Biol. 28:3441-3449. 
Grant P.R., Grant B.R. 2019. Hybridization increases population variation during adaptive radiation. Proc. Natl. Acad. Sci. U. S. A. 116:23216-23224.

Gravel S. 2012. Population genetics models of local ancestry. Genetics. 191:607-619.

Gronau I., Hubisz M.J., Gulko B., Danko C.G., Siepel A. 2011. Bayesian inference of ancient human demography from individual genome sequences. Nat. Genet. 43:1031-1035.

Hahn M.W., Nakhleh L. 2016. Irrational exuberance for resolved species trees. Evolution. 70:717.

Haig S.M., Allendorf F.W. 2006. Hybrids and Policy. In: Scott J.M., Goble D.D., Davis F., editors. The Endangered Species Act at Thirty: Conserving Biodiversity in HumanDominated Landscapes. Island Press. p. 150-163.

Hinrichs A.S., Karolchik D., Baertch R., Barber G.P., Bejerano G., Clawson H., Diekhans M., Furey T.S., Harte R.A., Hsu F., Hillman-Jackson J., Kuhn R.M., Pederson J.S., Pohl A., Raney B.J., Rosenbloom K.R., Siepel A., Smith K.E., Sugnet C.W., Sultan-Qurraie A., Thomas D.J., Trumbower H., Weber R.J., Weirauch M., Zweig A.S., Haussler D., Kent W.J. 2006. The UCSC Genome Browser Database: update 2006. Nucleic Acids Res. 34:D590-D598.

Hobolth A., Christensen O.F., Mailund T., Schierup M.H. 2007. Genomic relationships and speciation times of human, chimpanzee, and gorilla inferred from a coalescent hidden Markov model. PLoS Genet. 3:0294-0304.

Hoeppner M.P., Lundquist A., Pirun M., Meadows J.R.S., Zamani N., Johnson J., Sundström G., Cook A., FitzGerald M.G., Swofford R., Mauceli E., Moghadam B.T., Greka A., Alföldi J., Abouelleil A., Aftuck L., Bessette D., Berlin A., Brown A., Gearin G., Lui A., Macdonald J.P., Priest M., Shea T., Turner-Maier J., Zimmer A., Lander E.S., Di Palma F., Lindblad-Toh K., Grabherr M.G. 2014. An improved canine genome and a comprehensive catalogue of coding genes and non-coding transcripts. PLoS One. 9:e91172.

Hohenlohe P.A., Rutledge L.Y., Waits L.P., Andrews K.R., Adams J.R., Hinton J.W., Nowak R.M., Patterson B.R., Wydeven A.P., Wilson P.A., White B.N. 2017. Comment on "Whole genome sequence analysis shows two endemic species of North American Wolf are admixtures of the coyote and gray Wolf." Sci. Adv. 3:1-4.

Hudson R.R., Kaplan N.L. 1985. Statistical properties of the number of recombination events in the history of a sample of DNA sequences. Genetics. 111:147-164.

Hvala J.A., Frayer M.E., Payseur B.A. 2018. Signatures of hybridization and speciation in genomic patterns of ancestry. Evolution.:1540-1552.

Jackiw R.N., Mandil G., Hager H.A. 2015. A framework to guide the conservation of species hybrids based on ethical and ecological considerations. Conserv. Biol. 29:1040-1051. 
Jones M.R., Mills L.S., Alves P.C., Callahan C.M., Alves J.M., Lafferty D.J.R., Jiggins F.M., Jensen J.D., Melo-Ferreira J., Good J.M. 2018. Adaptive introgression underlies polymorphic seasonal camouflage in snowshoe hares. Science. 360:1355-1358.

Kays R., Curtis A., Kirchman J.J. 2010. Rapid adaptive evolution of northeastern coyotes via hybridization with wolves. Biol. Lett. 6:89-93.

Kirkness E.F., Bafna V., Halpern A.L., Levy S., Remington K., Rusch D.B., Delcher A.L., Pop M., Wang W., Fraser C.M., Venter J.C. 2003. The dog genome: Survey sequencing and comparative analysis. Science. 301:1898-1903.

Kishino H., Miyata T., Hasegawa M. 1990. Maximum likelihood inference of protein phylogeny and the origin of chloroplasts. J. Mol. Evol. 31:151-160.

Kukekova A. V, Johnson J.L., Xiang X., Feng S., Liu S., Rando H.M., Kharlamova A. V, Herbeck Y., Serdyukova N.A., Xiong Z., Beklemischeva V., Koepfli K., Gulevich R.G., Vladimirova A. V, Hekman J.P., Perelman P.L., Graphodatsky A.S. 2018. Red fox genome assembly identifies genomic regions associated with tame and aggressive behaviours. Nat. Ecol. Evol. 2:1479-1491.

Lamichhaney S., Han F., Webster M.T., Andersson L., Grant B.R., Grant P.R. 2018. Rapid hybrid speciation in Darwin's finches. Science. 359:224-228.

Langmead B., Salzberg S.L. 2012. Fast gapped-read alignment with Bowtie 2. Nat. Methods. 9:357-359.

Leache A.D., Harris R.B., Rannala B., Yang Z. 2014. The influence of gene flow on species tree estimation: A simulation study. Syst. Biol. 63:17-30.

Lehman N., Eisenhawer A., Hansen K., Mech L.D., Peterson R.O., Gogan P.J.P., Wayne R.K. 1991. Introgression of coyote mitochondrial DNA into sympatric North American gray wolf populations. Evolution. 45:104.

Lewontin R.C., Birch L.C. 2006. Hybridization as a source of variation for adaptation to new environments. Evolution. 20:315.

Li G., Figueiró H. V., Eizirik E., Murphy W.J., Yoder A. 2019. Recombination-aware phylogenomics reveals the structured genomic landscape of hybridizing cat species. Mol. Biol. Evol. 36:2111-2126.

Li H., Durbin R. 2011. Inference of human population history from individual whole-genome sequences. Nature.

Li H., Handsaker B., Wysoker A., Fennell T., Ruan J., Homer N., Marth G., Abecasis G., Durbin R. 2009. The sequence alignment/map format and SAMtools. Bioinformatics. 25:20782079.

Liang M., Nielsen R. 2014. The lengths of admixture tracts. Genetics. 197:953-967. 
Lind-Riehl J.F., Mayer A.L., Wellstead A.M., Gailing O. 2016. Hybridization, agency discretion, and implementation of the U.S. Endangered Species Act. Conserv. Biol. 30:1288-1296.

Lindblad-Toh K., Wade C.M., Mikkelsen T.S., Karlsson E.K., Jaffe D.B., Kamal M., Clamp M., Chang J.L., Kulbokas E.J., Zody M.C., Mauceli E., Xie X., Breen M., Wayne R.K., Ostrander E.A., Ponting C.P., Galibert F., Smith D.R., DeJong P.J., Kirkness E., Alvarez P., Biagi T., Brockman W., Butler J., Chin C.W., Cook A., Cuff J., Daly M.J., DeCaprio D., Gnerre S., Grabherr M., Kellis M., Kleber M., Bardeleben C., Goodstadt L., Heger A., Hitte C., Kim L., Koepfli K.P., Parker H.G., Pollinger J.P., Searle S.M.J., Sutter N.B., Thomas R., Webber C., Lander E.S. 2005. Genome sequence, comparative analysis and haplotype structure of the domestic dog. Nature. 438:803-819.

Loog L., Thalmann O., Sinding M.H.S., Schuenemann V.J., Perri A., Germonpré M., Bocherens H., Witt K.E., Samaniego Castruita J.A., Velasco M.S., Lundstrøm I.K.C., Wales N., Sonet G., Frantz L., Schroeder H., Budd J., Jimenez E.L., Fedorov S., Gasparyan B., Kandel A.W., Lázničková-Galetová M., Napierala H., Uerpmann H.P., Nikolskiy P.A., Pavlova E.Y., Pitulko V. V., Herzig K.H., Malhi R.S., Willerslev E., Hansen A.J., Dobney K., Gilbert M.T.P., Krause J., Larson G., Eriksson A., Manica A. 2019. Ancient DNA suggests modern wolves trace their origin to a Late Pleistocene expansion from Beringia. Mol. Ecol.:1-15.

Maddison W. 1997. Gene trees in species trees. Syst. Biol. 46:523-536.

Mailund T., Dutheil J.Y., Hobolth A., Lunter G., Schierup M.H. 2011. Estimating divergence time and ancestral effective population size of Bornean and Sumatran orangutan subspecies using a coalescent hidden Markov model. PLoS Genet. 7:1-15.

Mailund T., Halager A.E., Westergaard M., Dutheil J.Y., Munch K., Andersen L.N., Lunter G., Prüfer K., Scally A., Hobolth A., Schierup M.H. 2012. A new isolation with migration model along complete genomes infers very different divergence processes among closely related great ape species. PLoS Genet. 8:e1003125.

Marques D.A., Meier J.I., Seehausen O. 2019. A combinatorial view on speciation and adaptive radiation. Trends Ecol. Evol. 34:531-544.

Martin S.H., Davey J.W., Salazar C., Jiggins C.D. 2019. Recombination rate variation shapes barriers to introgression across butterfly genomes. PLoS Biol. 17:1-28.

Mavarez J., Linares M. 2008. Homoploid hybrid speciation in animals. Mol. Ecol. 17:41814185.

McGaugh S.E., Heil C.S.S., Manzano-Winkler B., Loewe L., Goldstein S., Himmel T.L., Noor M.A.F. 2012. Recombination modulates how selection affects linked sites in Drosophila. PLoS Biol. 10:e1001422.

McKenna A., Hanna M., Banks E., Sivachenko A., Cibulskis K., Kernytsky A., Garimella K., Altshuler D., Gabriel S., Daly M., DePristo M.A. 2010. The Genome Analysis Toolkit: a MapReduce framework for analyzing next-generation DNA sequencing data. Genome 
Res. 20:1297-1303.

Meachen J.A., Janowicz A.C., Avery J.E., Sadleir R.W. 2014. Ecological changes in coyotes (Canis latrans) in response to the ice age megafaunal extinctions. PLoS One. 9:1-15.

Meachen J.A., Samuels J.X. 2012. Evolution in coyotes (Canis latrans) in response to the megafaunal extinctions. Proc. Natl. Acad. Sci. U. S. A. 109:4191-4196.

Meier J.I., Marques D.A., Mwaiko S., Wagner C.E., Excoffier L., Seehausen O. 2017. Ancient hybridization fuels rapid cichlid fish adaptive radiations. Nat. Commun. 8:14363.

Nachman M.W., Payseur B.A. 2012. Recombination rate variation and speciation: Theoretical predictions and empirical results from rabbits and mice. Philos. Trans. R. Soc. B Biol. Sci. 367:409-421.

Nguyen L.-T., Schmidt H.A., von Haeseler A., Minh B.Q. 2014. IQ-TREE: A fast and effective stochastic algorithm for estimating Maximum-Likelihood phylogenies. Mol. Biol. Evol. 32:268-274.

Ni X., Yuan K., Liu C., Feng Q., Tian L., Ma Z., Xu S. 2018a. MultiWaver 2.0: modeling discrete and continuous gene flow to reconstruct complex population admixtures. Eur. J. Hum. Genet. 27:133-139.

Ni X., Yuan K., Yang X., Feng Q., Guo W., Ma Z., Xu S. 2018b. Inference of multiple-wave admixtures by length distribution of ancestral tracks. Heredity. 121:52-63.

Nieto Feliner G., Álvarez I., Fuertes-Aguilar J., Heuertz M., Marques I., Moharrek F., Piñeiro R., Riina R., Rosselló J.A., Soltis P.S., Villa-Machío I. 2017. Is homoploid hybrid speciation that rare? An empiricist's view. Heredity. 118:513-516.

Nowak R.M. 1979. North American Quaternary Canis. Monogr. Museum Nat. Hist. Univ. Kansas. 6:154pp.

Nowak R.M. 1992. The red wolf is not a hybrid. Conserv. Biol. 6:593-595.

Nowak R.M. 2002. The original status of wolves in eastern North America. Southeast. Nat. 1:95-130.

O’Brien S.J., Mayr E. 1991. Bureaucratic mischief: Recognizing endangered species and subspecies. Science. 251:1187-1188.

Pardi M.I., Smith F.A. 2016. Biotic responses of canids to the terminal Pleistocene megafauna extinction. Ecography. 39:141-151.

Payseur B.A., Rieseberg L.H. 2016. A genomic perspective on hybridization and speciation. Mol. Ecol. 25:2337-2360.

Philippe H., Brinkmann H., Lavrov D. V., Littlewood D.T.J., Manuel M., Wörheide G., Baurain 
D. 2011. Resolving difficult phylogenetic questions: Why more sequences are not enough. PLoS Biol. 9:e1000602.

Pilot M., Moura A.E., Okhlopkov I.M., Mamaev N. V., Alagaili A.N., Mohammed O.B., Yavruyan E.G., Manaseryan N.H., Hayrapetyan V., Kopaliani N., Tsingarska E., Krofel M., Skoglund P., Bogdanowicz W. 2019. Global phylogeographic and admixture patterns in grey wolves and genetic legacy of an ancient Siberian lineage. Sci. Rep. 9:1-13.

Plummer M., Best N., Cowles K., Vines K. 2006. CODA: Convergence diagnosis and output analysis for MCMC. R News. 6:7-11.

Pool J.E., Nielsen R. 2009. Inference of historical changes in migration rate from the lengths of migrant tracts. Genetics. 181:711-719.

Presgraves D.C. 2018. Evaluating genomic signatures of "the large X-effect" during complex speciation. Mol. Ecol. 27:3822-3830.

Reich D.E., Wayne R.K., Goldstein D.B. 1999. Genetic evidence for a recent origin by hybridization of red wolves. Mol. Ecol. 8:139-144.

Rieseberg L.H., Linder C.R. 1999. Hybrid classification: Insights from genetic map-based studies of experimental hybrids. Ecology. 80:361-370.

Rosenberg N., Feldman M. 2002. The relationship between coalescence times and population divergence times. In: Slatkin M.L., Veuille M., editors. Devolopments in Theorical Populations Genetics. Oxford University Press. p. 130-159.

Roy M.S., Gefenj E., Wayne R.K., Smith D., Ostrander E.A. 1994. Patterns of differentiation and hybridization in North American wolflike canids, revealed by analysis of microsatellite loci. Mol. Biol. Evol. 11:553-570.

Roy M.S., Geffen E., Smith D., Wayne R.K. 1996. Molecular genetics of pre-1940 red wolves. Conserv. Biol. 10:1413-1424.

Runemark A., Fernández L.P., Eroukhmanoff F., Sætre G.P. 2018a. Genomic contingencies and the potential for local adaptation in a hybrid species. Am. Nat. 192:10-22.

Runemark A., Trier C.N., Eroukhmanoff F., Hermansen J.S., Matschiner M., Ravinet M., Elgvin T.O., Sætre G.P. 2018b. Variation and constraints in hybrid genome formation. Nat. Ecol. Evol. 2:549-556.

Schumer M., Rosenthal G.G., Andolfatto P. 2014. How common is homoploid hybrid speciation? Evolution. 68:1553-1560.

Schumer M., Rosenthal G.G., Andolfatto P. 2018a. What do we mean when we talk about hybrid speciation? Heredity. 120:379-382.

Schumer M., Xu C., Powell D.L., Durvasula A., Skov L., Holland C., Blazier J.C., Sankararaman 
S. 2018b. Natural selection interacts with recombination to shape the evolution of hybrid genomes. Science. 660:656-660.

Sedghifar A., Brandvain Y., Ralph P. 2016. Beyond clines: lineages and haplotype blocks in hybrid zones. Mol. Ecol. 25:2559-2576.

Seixas F.A., Boursot P., Melo-Ferreira J. 2018. The genomic impact of historical hybridization with massive mitochondrial DNA introgression. Genome Biol. 19:1-20.

Shen X.X., Hittinger C.T., Rokas A. 2017. Contentious relationships in phylogenomic studies can be driven by a handful of genes. Nat. Ecol. Evol. 1:1-10.

Siberchicot A., Bessy A., Guéguen L., Marais G.A.B. 2017. MareyMap online: A user-friendly web application and database service for estimating recombination rates using physical and geneticmaps. Genome Biol. Evol. 9:2506-2509.

Siepel A., Bejerano G., Pedersen J.S., Hinrichs A.S., Hou M., Rosenbloom K., Clawson H., Spieth J., Hillier L.D.W., Richards S., Weinstock G.M., Wilson R.K., Gibbs R.A., Kent W.J., Miller W., Haussler D. 2005. Evolutionarily conserved elements in vertebrate, insect, worm, and yeast genomes. Genome Res. 15:1034-1050.

Spence J.P., Steinrücken M., Terhorst J., Song Y.S. 2018. Inference of population history using coalescent HMMs: review and outlook. Curr. Opin. Genet. Dev. 53:70-76.

Springer M.S., Gatesy J. 2018. Delimiting coalescence genes (C-genes) in phylogenomic data sets. Genes. 9:1-19.

Stanke M., Waack S. 2003. Gene prediction with a hidden Markov model and a new intron submodel. Bioinformatics. 19:215-225.

Supple M.A., Shapiro B. 2018. Conservation of biodiversity in the genomics era. Genome Biol. 19:1-12.

Taylor S.A., Larson E.L. 2019. Insights from genomes into the evolutionary importance and prevalence of hybridization in nature. Nat. Ecol. Evol. 3:170-177.

Twyford A.D., Ennos R.A. 2012. Next-generation hybridization and introgression. Heredity. 108:179-189.

vonHoldt B.M., Brzeski K.E., Wilcove D.S., Rutledge L.Y. 2018. Redefining the role of admixture and genomics in species conservation. Conserv. Lett. 11:1-6.

vonHoldt B.M., Cahill J.A., Fan Z., Gronau I., Robinson J., Pollinger J.P., Shapiro B., Wall J., Wayne R.K. 2016a. Whole-genome sequence analysis shows that two endemic species of North American wolf are admixtures of the coyote and gray wolf. Sci. Adv. 2:e1501714e1501714.

vonHoldt B.M., Cahill J.A., Gronau I., Shapiro B., Wall J., Wayne R.K. 2017. Response to 
Hohenlohe et al. Sci. Adv. 3:1-3.

vonHoldt B.M., Kays R., Pollinger J.P., Wayne R.K. 2016b. Admixture mapping identifies selectively introgressed genomic regions in North American canids. Mol. Ecol. 25:24432453.

vonHoldt B.M., Pollinger J.P., Earl D.A., Knowles J.C., Boyko A.R., Parker H., Geffen E., Pilot M., Jedrzejewski W., Jedrzejewska B., Sidorovich V., Greco C., Randi E., Musiani M., Kays R., Bustamante C.D., Ostrander E.A., Novembre J., Wayne R.K. 2011. A genomewide perspective on the evolutionary history of enigmatic wolf-like canids. Genome Res. 21:1294-1305.

Waples R.S., Kays R., Fredrickson R.J., Pacifici K., Mills L.S. 2018. Is the red wolf a listable unit under the US Endangered Species Act? J. Hered. 109:585-597.

Wayne R.K., Jenks S.M. 1991. Mitochondrial DNA analysis implying extensive hybridization of the endangered red wolf Canis rufus. Nature. 351:565-568.

Wilson P.J., Grewal S., Lawford I.D., Heal J.N.M., Granacki A.G., Pennock D., Theberge J.B., Theberge M.T., Voigt D.R., Waddell W., Chambers R.E., Paquet P.C., Goulet G., Cluff D., White B.N. 2000. DNA profiles of the eastern Canadian wolf and the red wolf provide evidence for a common evolutionary history independent of the gray wolf. Can. J. Zool. 78:2156-2166.

Wong A.K., Neff M.W. 2009. DOGSET: Pre-designed primer sets for fine-scale mapping and DNA sequence interrogation in the dog. Anim. Genet. 40:569-571.

Wong A.K., Ruhe A.L., Dumont B.L., Robertson K.R., Guerrero G., Shull S.M., Ziegle J.S., Millon L. V., Broman K.W., Payseur B.A., Neff M.W. 2010. A comprehensive linkage map of the dog genome. Genetics. 184:595-605.

Yakimowski S.B., Rieseberg L.H. 2014. The role of homoploid hybridization in evolution: A century of studies synthesizing genetics and ecology. Am. J. Bot. 101:1247-1258.

Yang Z. 1995. A space-time process model for the evolution of DNA sequences. Genetics. 139:993-1005.

Zhou Y., Yuan K., Yu Y., Ni X., Xie P., Xing E.P., Xu S. 2017. Inference of multiple-wave population admixture by modeling decay of linkage disequilibrium with polynomial functions. Heredity. 118:503-510. 


\section{Figures and Tables}

Table 1: Recombination rate differences between homozygous and heterozygous ancestry blocks

4 in autosomes versus the X-chromosome. Recombination rate is reported as the ratio of centimorgan $(\mathrm{cM})$ per $\mathrm{Mb}$ and partitioned into homozygous coyote and gray wolf ancestry and

6 heterozygous ancestry (=HET). Significance is reported for Mann-Whitney $U$ test comparing Xchromosome and autosome $\mathrm{cM} / \mathrm{Mb}$ within each partition.

8

\begin{tabular}{rrrrll} 
& \multicolumn{3}{c}{ AUTOSOMES } & \multicolumn{3}{c}{ X-ONLY } & \\
& $\mathrm{cM} / \mathrm{Mb}$ & $N$ & $\mathrm{cM} / \mathrm{Mb}$ & $N$ & $P$-value \\
\hline PHY subset & & & & & \\
Coyote & 1.00 & 22996 & 0.97 & 2087 & \\
Gray Wolf & 1.01 & 16648 & 1.15 & 940 & $<0.0001$ \\
Het. & 1.14 & 3859 & 1.03 & 43 & $<0.0001$ \\
All blocks & & & & & \\
Coyote & 1.07 & 90978 & 1.05 & 4477 & \\
Gray Wolf & 1.07 & 101999 & 1.13 & 3158 & $<0.0001$ \\
Het. & 1.06 & 106550 & 1.03 & 509 & \\
\hline
\end{tabular}


Figure 1: Effect of recombination rate on genomic ancestry proportions (A) and absolute divergence times (B) in the red wolf genome, partitioned among autosomes and X-chromosome. Percent ancestry is computed among genomic ancestry blocks which could be assigned as heterozygous (green), homozygous gray-wolf (blue), or homozygous coyote (red). Genomic representation is reported both as percentage of ancestry blocks (solid) and percentage of basepairs (bp; dashed). Divergence times $(\tau)$ measured in expected substitutions were estimated using coalescent hidden Markov models (coalHMM) applied to 1Mb blocks. Results are further partitioned by local recombination rate $(\mathrm{cM} / \mathrm{Mb})$ binned as 'high' $(>=2.0)$, 'moderate' $(0.5-2.0)$, and 'low' (<=0.5), and show posterior estimates of: 1$)$ red wolf-coyote divergence $\left(\tau_{\mathrm{COY}} ;\right.$ red $) ; 2$ ) red wolf-gray wolf divergence $\left(\tau_{\mathrm{WOLF}}\right.$; blue); and 3$)$ the time of post-hybridization isolation $\left(\tau_{\mathrm{H}}\right.$; green).

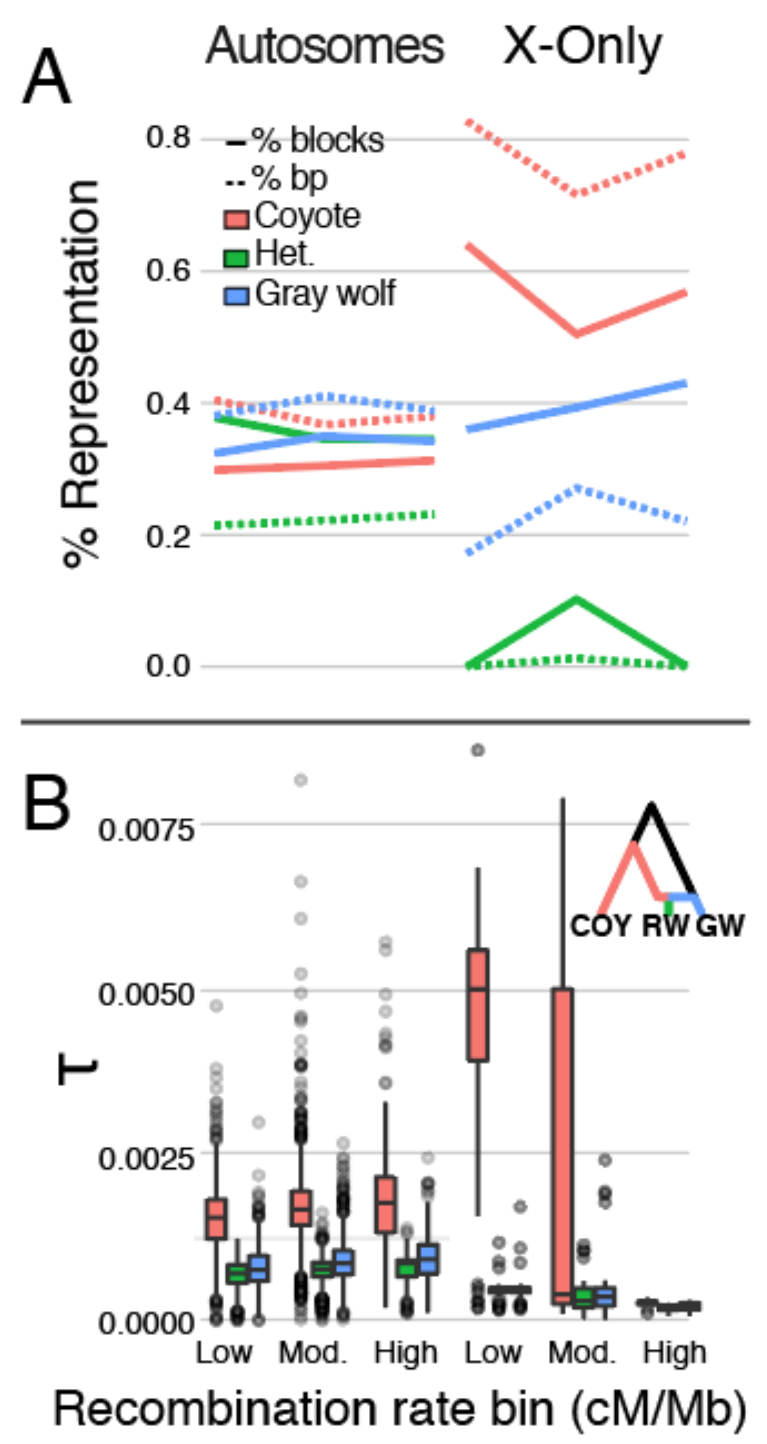


Figure 2: Divergence times estimated using G-PHOCS applied to parental sub-genomes of the red wolf. Divergence times $(\tau)$ measured in expected substitutions are shown for the red wolfcoyote divergence $\left(\tau_{\mathrm{COY}}\right.$; red) and red wolf-gray wolf divergence $\left(\tau_{\mathrm{WOLF}}\right.$; blue). Values are scaled up by a factor of 10,000 (left y-axis) and also provided in calibrated form (right y-axis) in thousands of years, assuming a generation time of three years and an average per-generation mutation rate of $\mu=4 \times 10^{-9} /$ base pair.

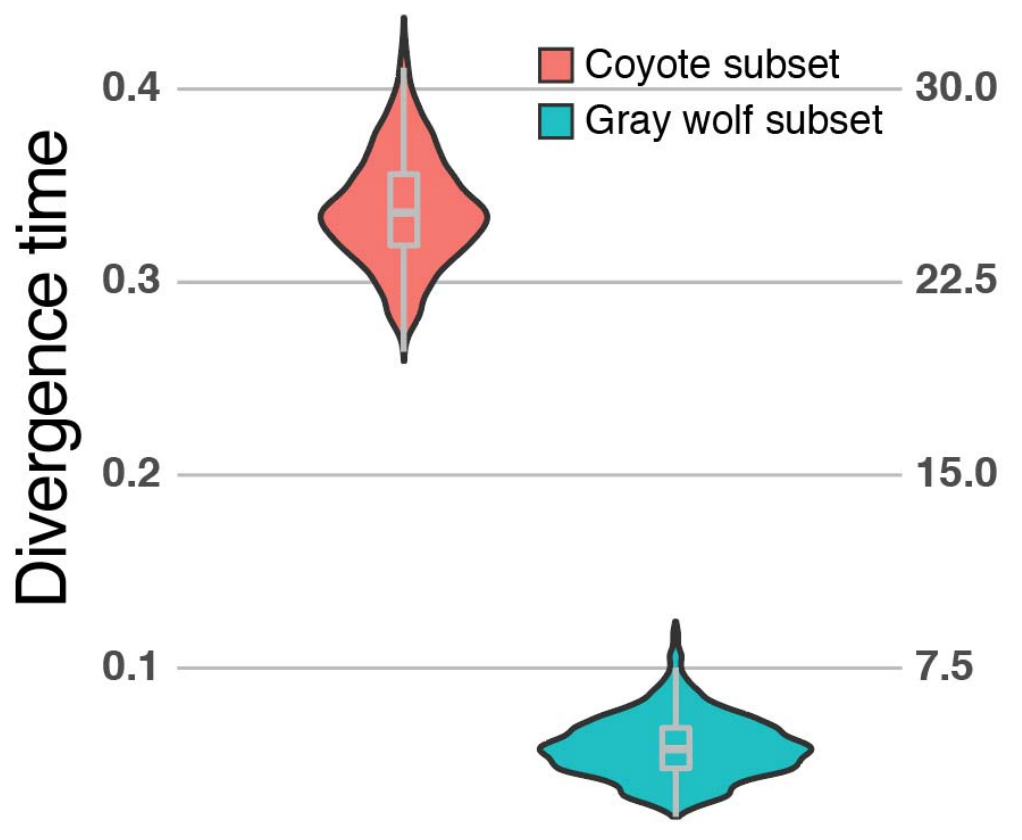


34 Figure 3: Distribution of interspecific heterozygosity in the red wolf genome, and inferred divergence ages (inset) within low ( $<0.1$ mean interspecific heterozygosity) and high $(>=0.1)$ regions of autosomes. Interspecific heterozygosity was computed as a weighted mean among delimited ancestry blocks encompassed by $1 \mathrm{Mb}$ non-overlapping sliding windows.

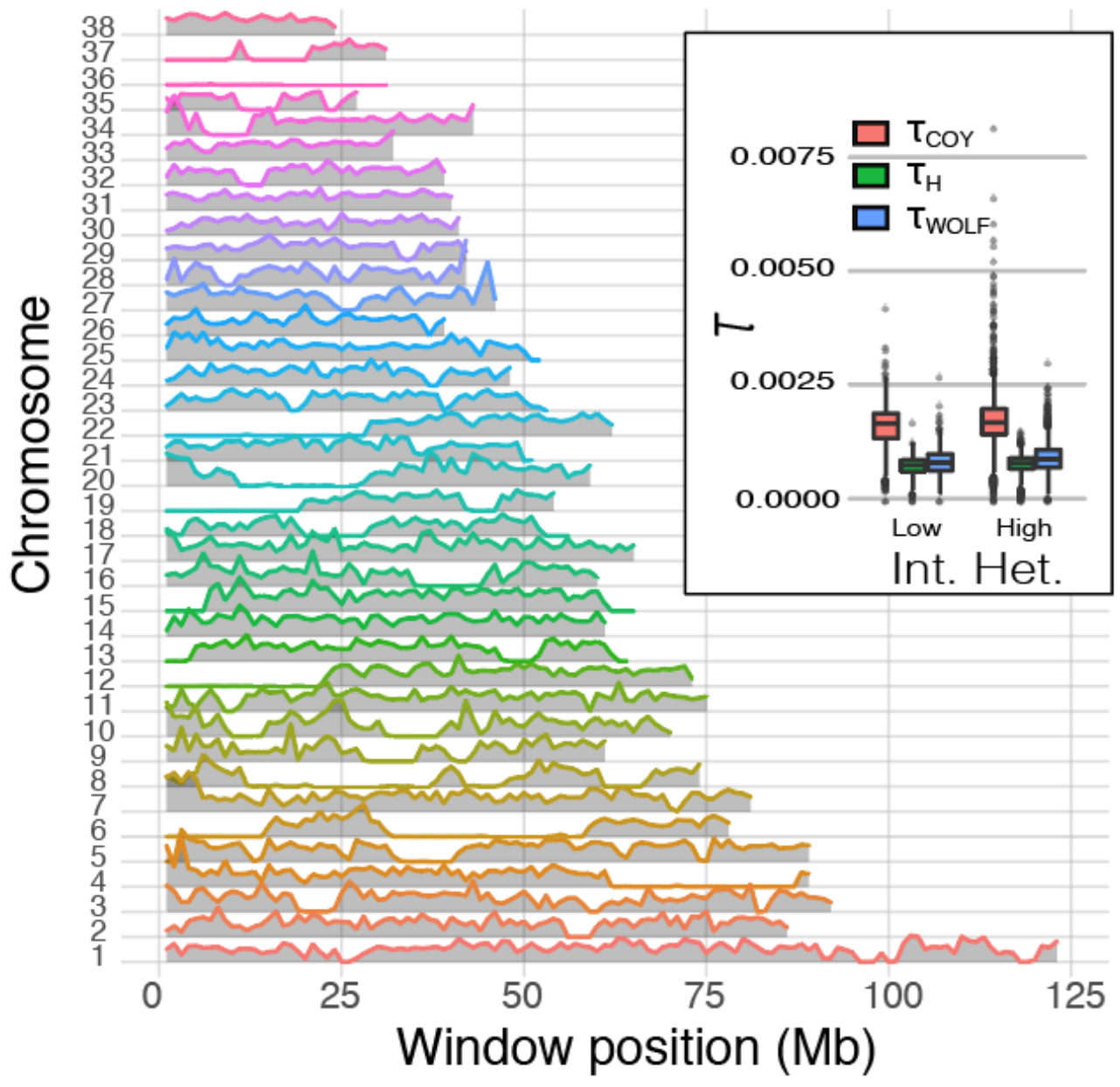


Figure 4: Times of inferred admixture events from coyote (above) and gray wolf (below) into the red wolf genome, measured in generations before the present. Results are shown aggregated from all chromosomes, excluding $\mathrm{N}=3$ chromosomes for which a single-pulse gradual admixture

44 model was selected.

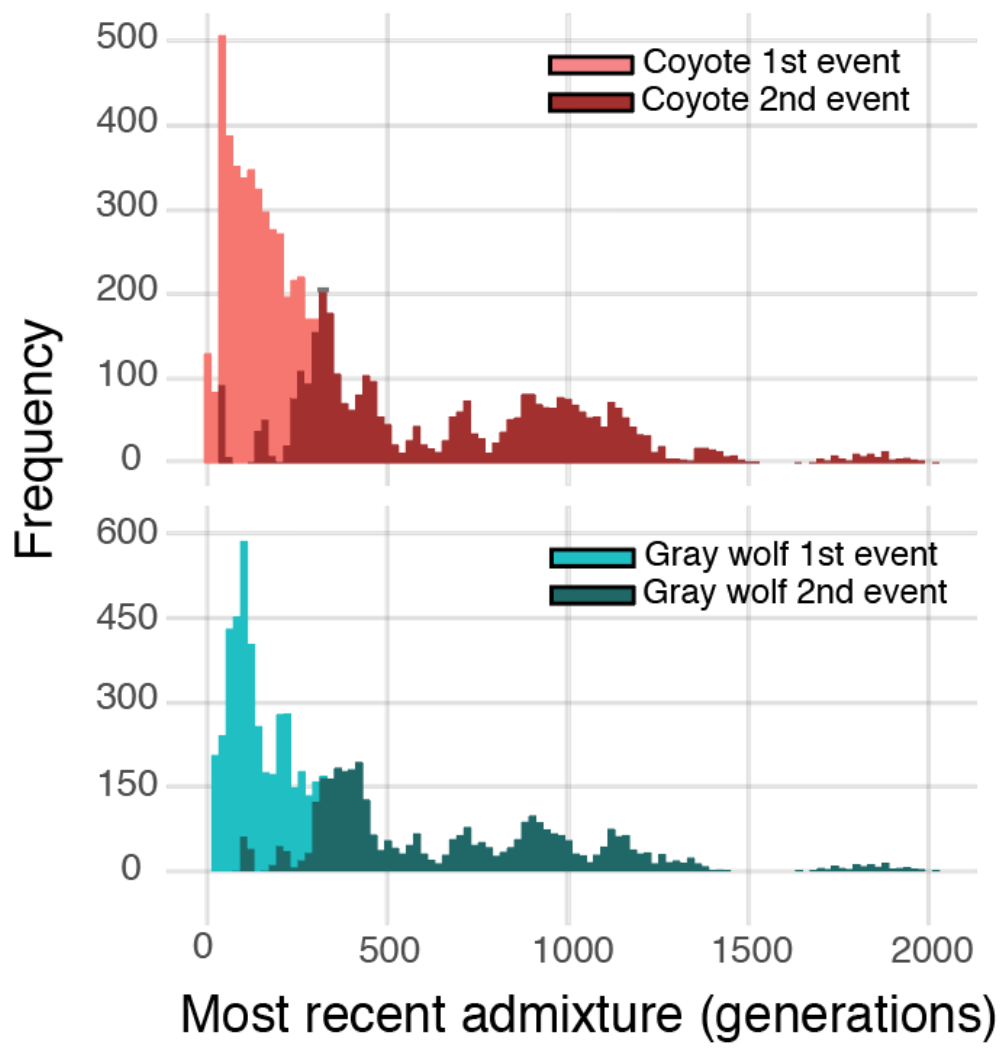




\section{Supplemental Figures and Tables}

52 Table S1: Ancestry proportions of the red wolf genome at varying filtering thresholds and metrics of inclusion. Values are reported as proportion of bases, with proportion of blocks in

54 parentheses. Note that here, 'Unassigned' reflects regions in which neither ancestries could be assigned (e.g. red wolf sister to outgroup).

56

\begin{tabular}{lllcc} 
Filtering criterion & Coyote & Gray Wolf & Heterozygous & Unassigned \\
\hline No filters & $0.252(0.204)$ & $0.232(0.365)$ & $0.337(0.365)$ & $0.179(0.214)$ \\
Exc. unassigned blocks & $0.311(0.262)$ & $0.417(0.470)$ & $0.272(0.268)$ & - \\
$\quad+0.9>$ int.het $<0.1$ & $0.426(0.310)$ & $0.376(0.341)$ & $0.198(0.349)$ & - \\
$\quad+$ bp.RELL $<0.10$ & $0.511(0.390)$ & $0.280(0.284)$ & $0.208(0.326)$ & - \\
Exc. heterozygous & $0.437(0.377)$ & $0.386(0.415)$ & - & $0.177(0.207)$ \\
$\quad+$ bp.RELL $<0.10$ & $0.431(0.264)$ & $0.234(0.185)$ & - & $0.335(0.550)$ \\
Exc. unassigned and heterozygous & $0.531(0.476)$ & $0.469(0.524)$ & - & - \\
\multicolumn{1}{c}{+ bp.RELL $<0.10$} & $0.648(0.588)$ & $0.352(0.412)$ & - & - \\
\hline
\end{tabular}


60 Table S2: Mutation-scaled and absolute divergence time estimates from g-PhoCS. Parameters are as follows: population divergence time for red wolf and coyote $\left(\tau_{\mathrm{COY}}\right)$; divergence time for

62 red wolf and gray wolf $\left(\tau_{\mathrm{WOLF}}\right)$; divergence time for all Canis species $\left(\tau_{\mathrm{CANIS}}\right)$; and the divergence time for the root $\left(\tau_{\mathrm{ALL}}\right)$. Values shown are the raw arithmetic mean estimates, with 64 calibrated estimates in years in parentheses, assuming a generation time of three years and an average per-generation mutation rate of $\mu=4 \times 10^{-9} /$ base pair.

66

\begin{tabular}{ccccc} 
Analysis & $\tau_{\mathrm{COY}}$ & $\tau_{\mathrm{WOLF}}$ & $\tau_{\mathrm{CANIS}}$ & $\tau_{\text {ALL }}$ \\
\hline Coyote subset & $3.8 \times 10^{-5}$ & - & $7.3 \times 10^{-4}$ & $2.5 \times 10^{-3}$ \\
& $(28,500)$ & & $(547,500)$ & $(1,875,000)$ \\
Gray wolf subset & - & $5.9 \times 10^{-6}(4,425)$ & $7.6 \times 10^{-4}$ & $2.9 \times 10^{-3}$ \\
& & & $(570,000)$ & $(2,175,000)$ \\
\hline
\end{tabular}

68 
Figure S1: Ancestry block lengths in the red wolf genome before (A) and after (B) merging 72 consecutive blocks of the same ancestry. Note truncation of the x-axis for interpretability.

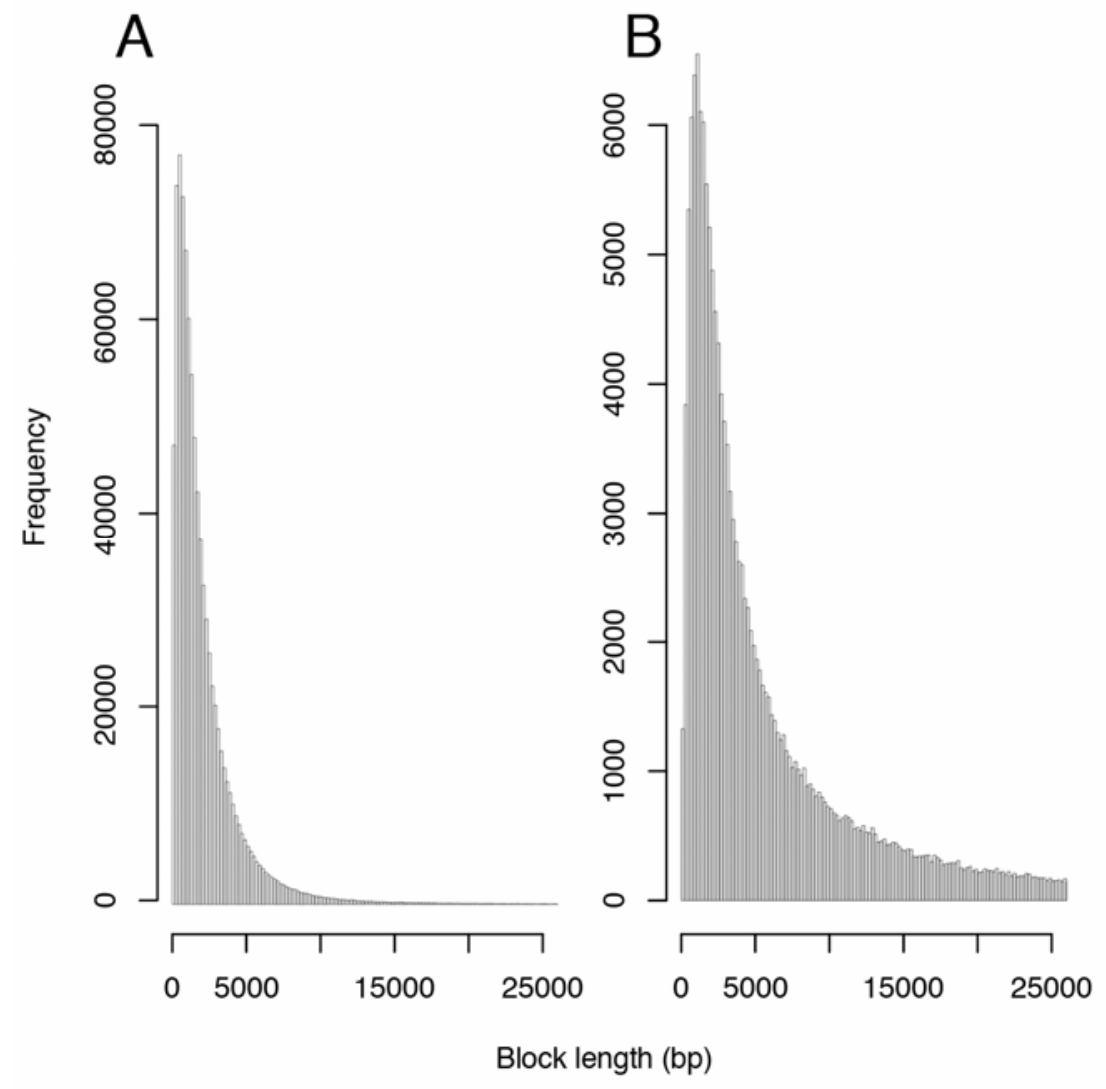


bioRxiv preprint doi: https://doi.org/10.1101/2020.04.05.026716; this version posted April 6, 2020. The copyright holder for this preprint (which

was not certified by peer review) is the author/funder, who has granted bioRxiv a license to display the preprint in perpetuity. It is made available under aCC-BY-NC-ND 4.0 International license.

76 Figure S2: Cubic interpolation models for red wolf chromosomes (black) with points depicting datapoints from the genetic map (red)

78
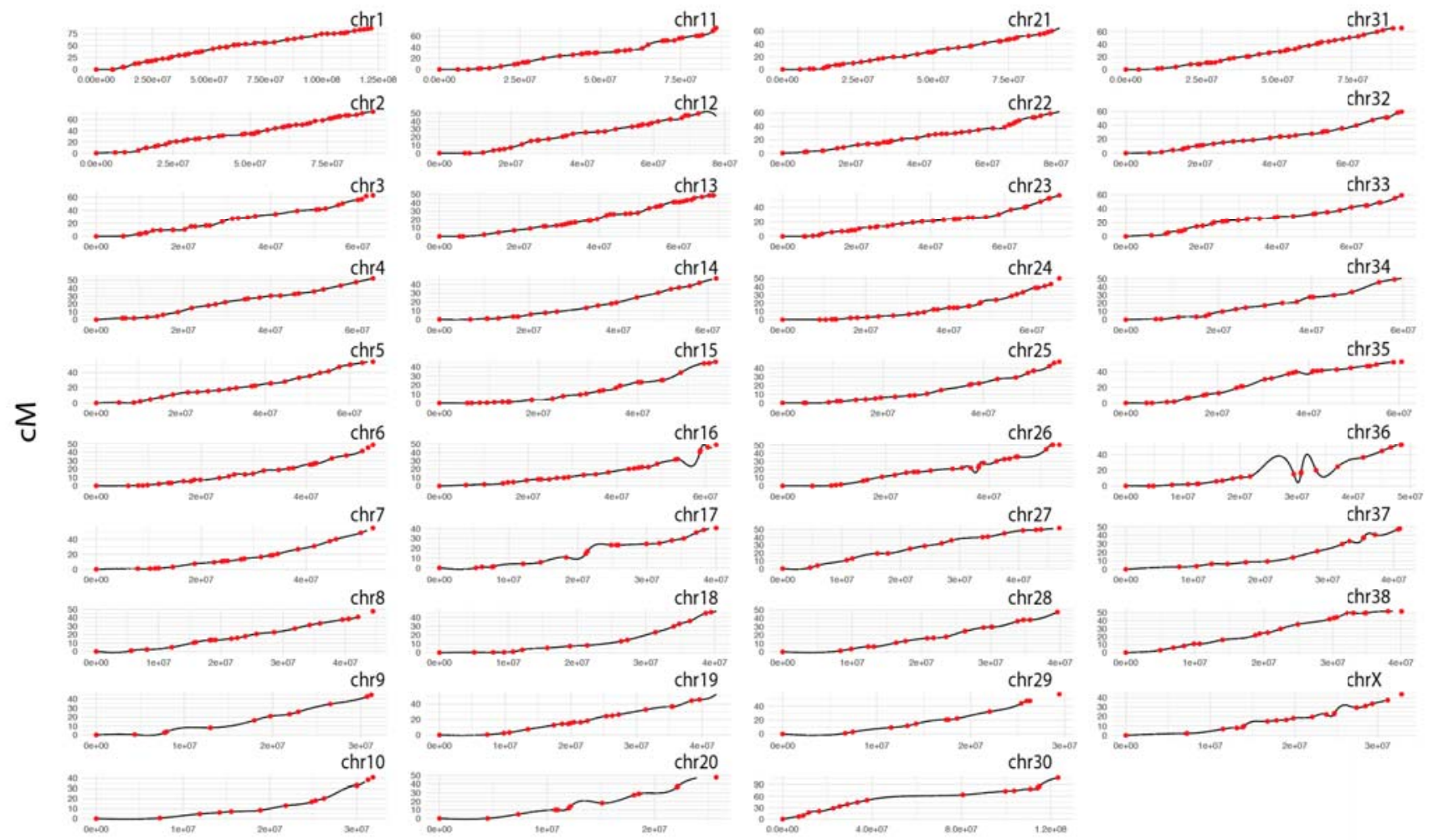

Physical position (bp) 
82 Figure S3: Densitree plot (A) of gene trees and distribution of interspecific heterozygosity (B) among sampled genomic ancestry blocks in the red wolf genome. Gene trees are restricted to

84 those which were significantly supported by approximated bootstrap proportions (e.g. $<10 \%$ of trees supporting an alternate topology), whereas interspecific heterozygosity is reported for all

86 blocks.

A

Vulpes vulpes

Canis lupus

Canis rufus

Canis latrans

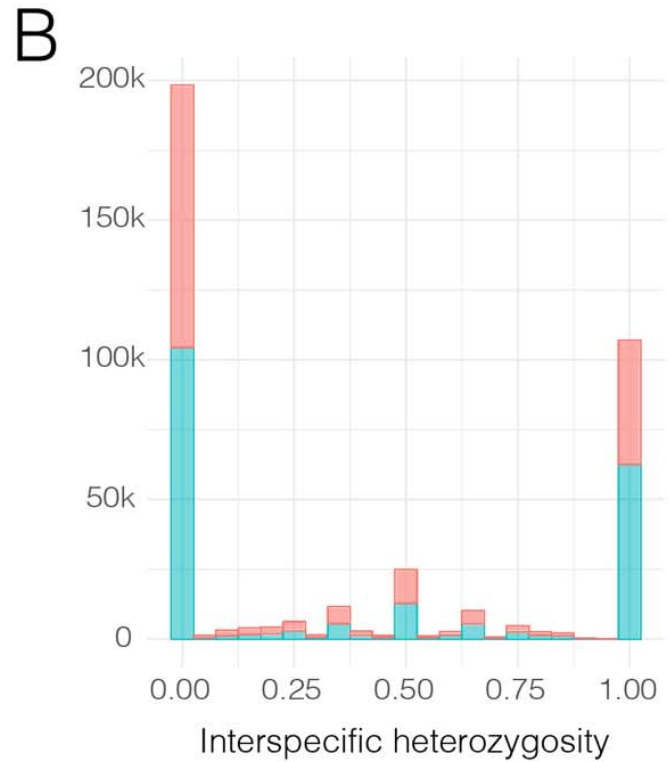

Interspecific heterozygosity 
bioRxiv preprint doi: https://doi.org/10.1101/2020.04.05.026716; this version posted April 6, 2020. The copyright holder for this preprint (which was not certified by peer review) is the author/funder, who has granted bioRxiv a license to display the preprint in perpetuity. It is made available under aCC-BY-NC-ND 4.0 International license.

Figure S4: Dominant ancestries summarized along red wolf chromosomes, as determined via 'majority-rule' among delimited ancestry blocks merged into 500kb segments, excluding blocks for which ancestry could not be decisively determined.

92

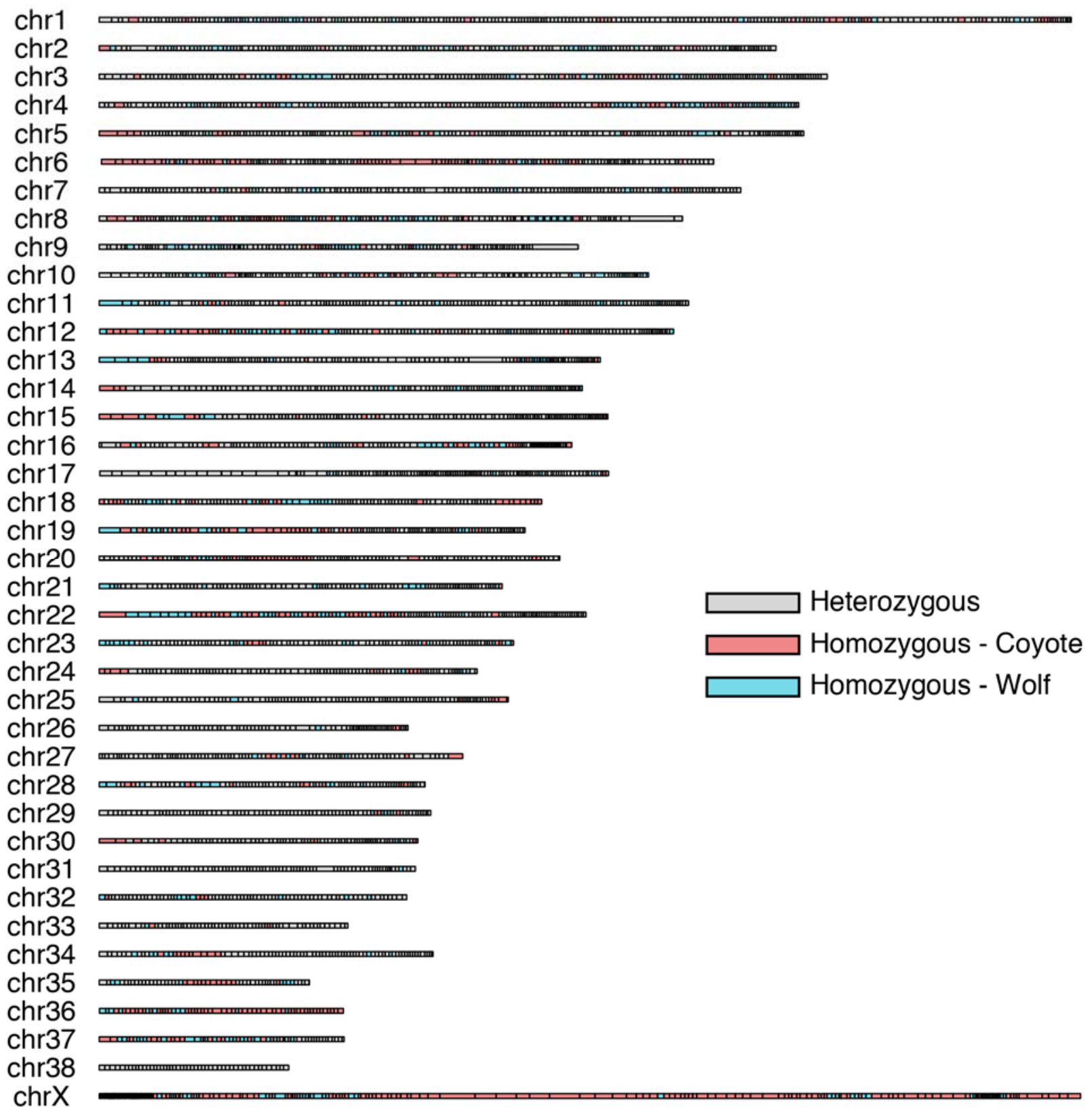


bioRxiv preprint doi: https://doi.org/10.1101/2020.04.05.026716; this version posted April 6, 2020. The copyright holder for this preprint (which was not certified by peer review) is the author/funder, who has granted bioRxiv a license to display the preprint in perpetuity. It is made available under aCC-BY-NC-ND 4.0 International license.

96 Figure S5: Proportion of assigned ancestries in the red wolf genome in 1 megabase blocks per chromosome, with blocks that could not be conclusively called as heterozygous or parental-

98 homozygous excluded.

100

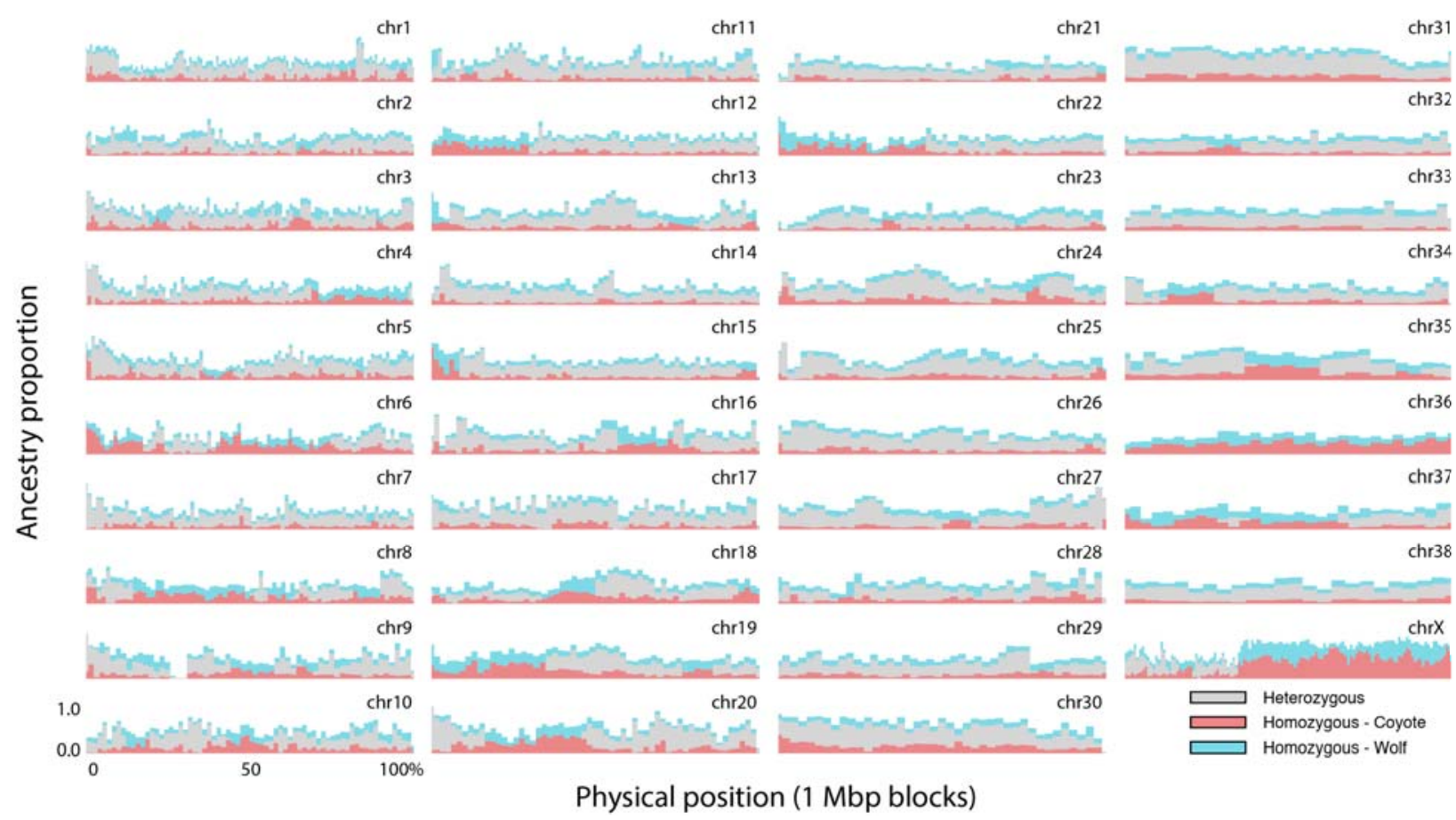


Figure S6: Histogram of Gelman convergence diagnostics across MCMC chains (each having 104 two replicates), showing a cutoff threshold (red) of 1.05. Values shown are post burn-in, following an automated iterative procedure testing burn-in values according to the Geweke 106 diagnostic.

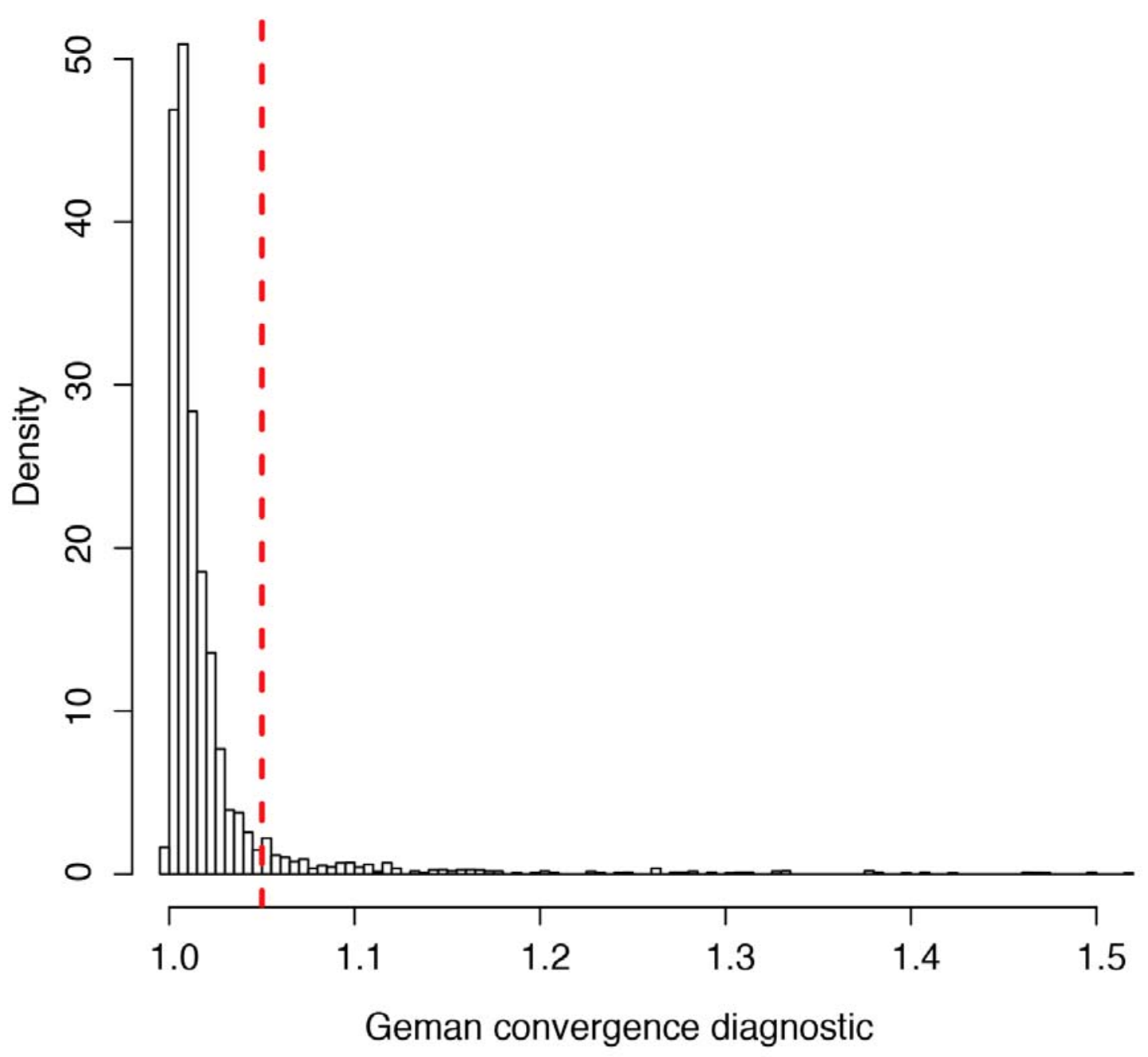


110 Figure S7: Effective sample sizes summarized across coalHMM MCMC chains passing Gelman-Rubin convergence threshold of 1.05. The minimum ESS threshold (red) of 100 was 112 used to filter coalHMM results.

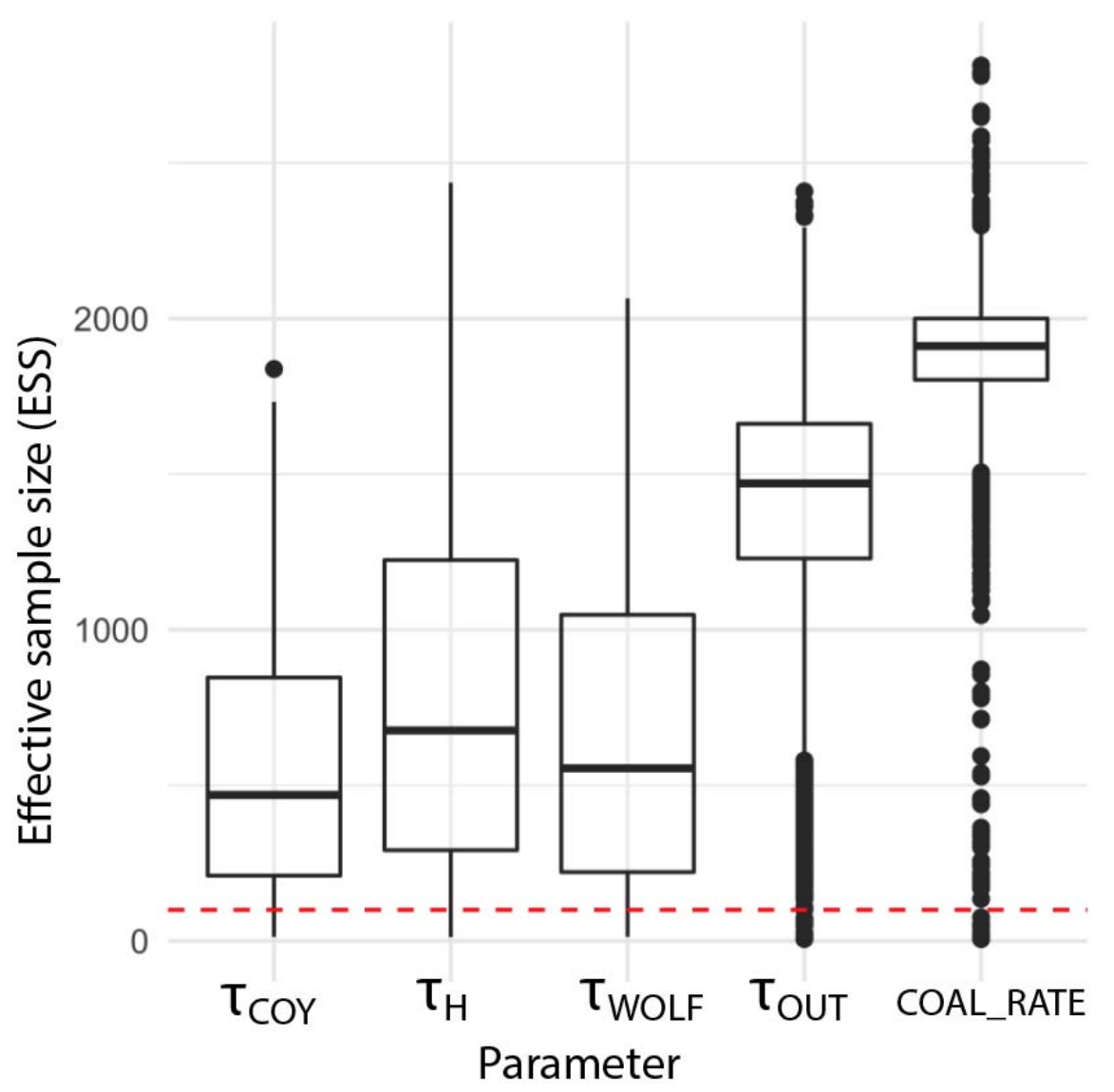


116 Figure S8: Posterior distributions of coalescent times inferred using coalHMM within $1 \mathrm{Mb}$ blocks of the red wolf genome (A) and the ratios among dates (B)

118
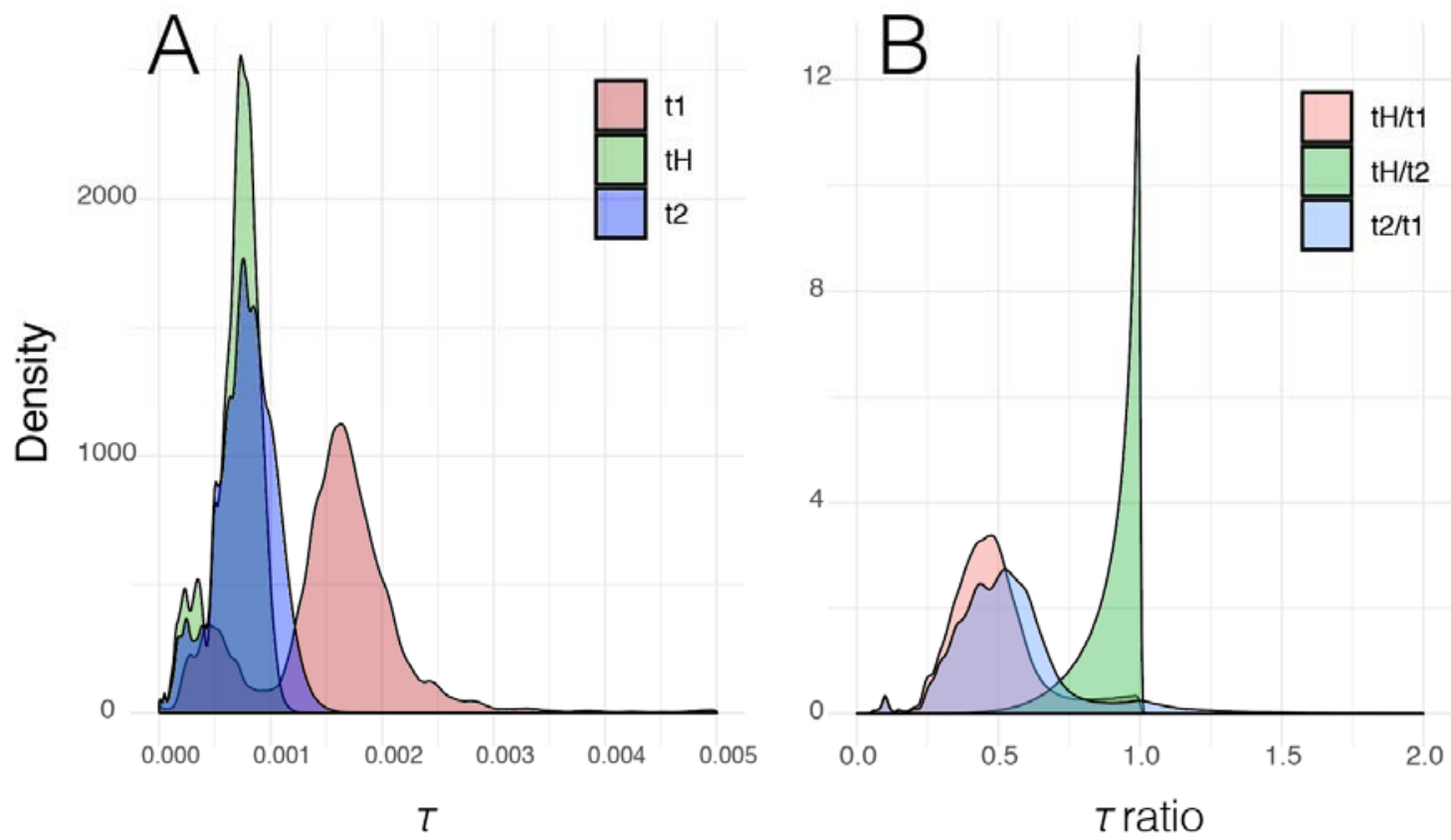
122 Results are grouped by putative coyote and gray wolf sub-genomes, showing mutation-scaled effective population size $(\Theta)$ and divergence times $(\tau)$. Both analyses assumed a pectinate tree,

124 wherein the 'source' (=parental) genome is sister to the red wolf, with Vulpes vulpes as an outgroup. Parameters are displayed on a log scale, and are as follows: Effective population size

126 for the source genome for each respective subset $\left(\Theta_{\text {SISTER }}\right)$; effective population size for red wolf $\left(\Theta_{\mathrm{RW}}\right)$; population size of the non-source genome (e.g. coyote for gray wolf sub-genome

128 analysis; $\left.\Theta_{\mathrm{ALT}}\right)$; ancestral population size for red wolf and the source genome $\left(\Theta_{\mathrm{ANC}}\right)$; ancestral population size for all Canis species $\left(\Theta_{\mathrm{CANIS}}\right)$; ancestral population size for the root $\left(\Theta_{\mathrm{ALL}}\right)$;

130 population divergence time for red wolf and the source genome $\left(\tau_{\mathrm{ANC}}\right)$; divergence time for all Canis species $\left(\tau_{\mathrm{CANIS}}\right)$; and the divergence time for the root $\left(\tau_{\mathrm{ALL}}\right)$.

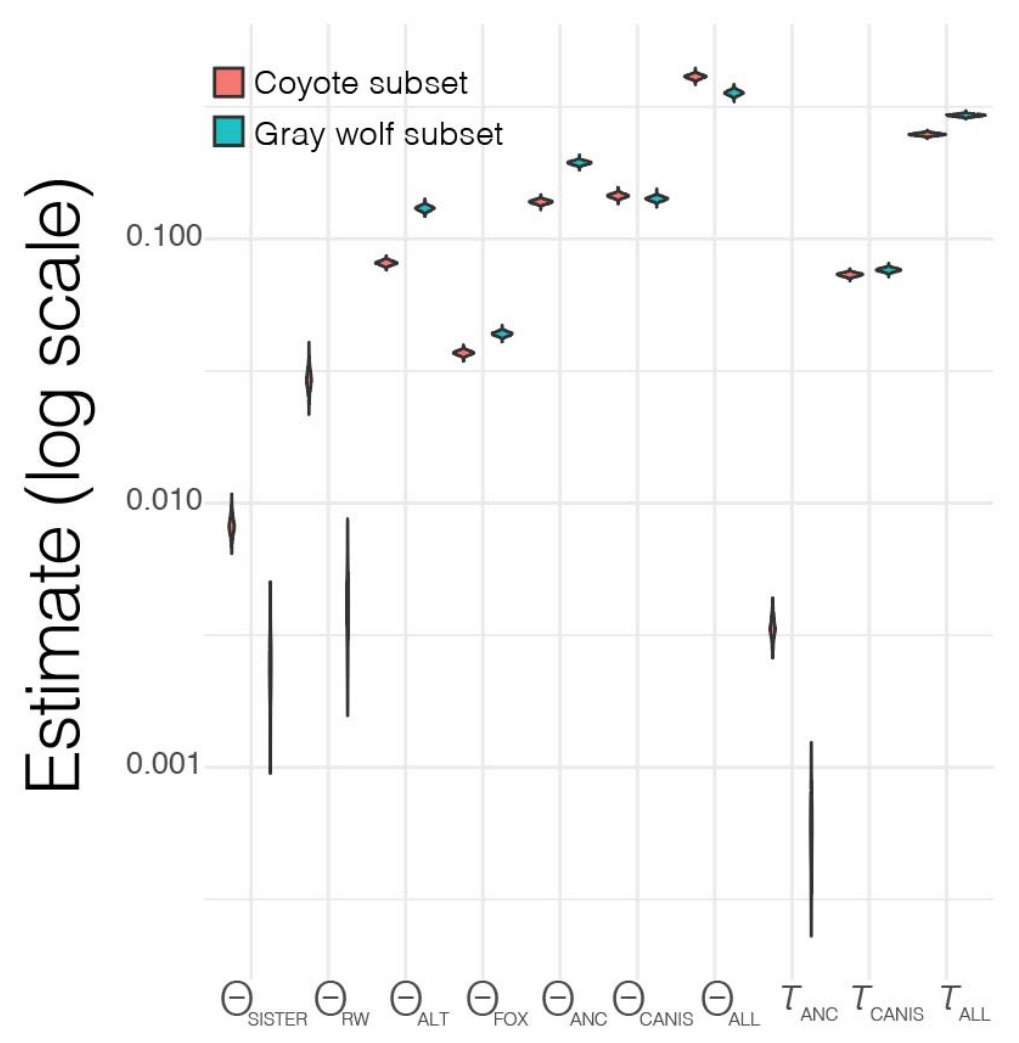


Figure S10: Total count of chromosomes choosing categories of admixture models, where GA=gradual admixture; and Multi_ $x$ - $y$ represents multiple-pulse admixture models where $x=$ number of inferred coyote admixture events and $y=$ number of gray wolf events.

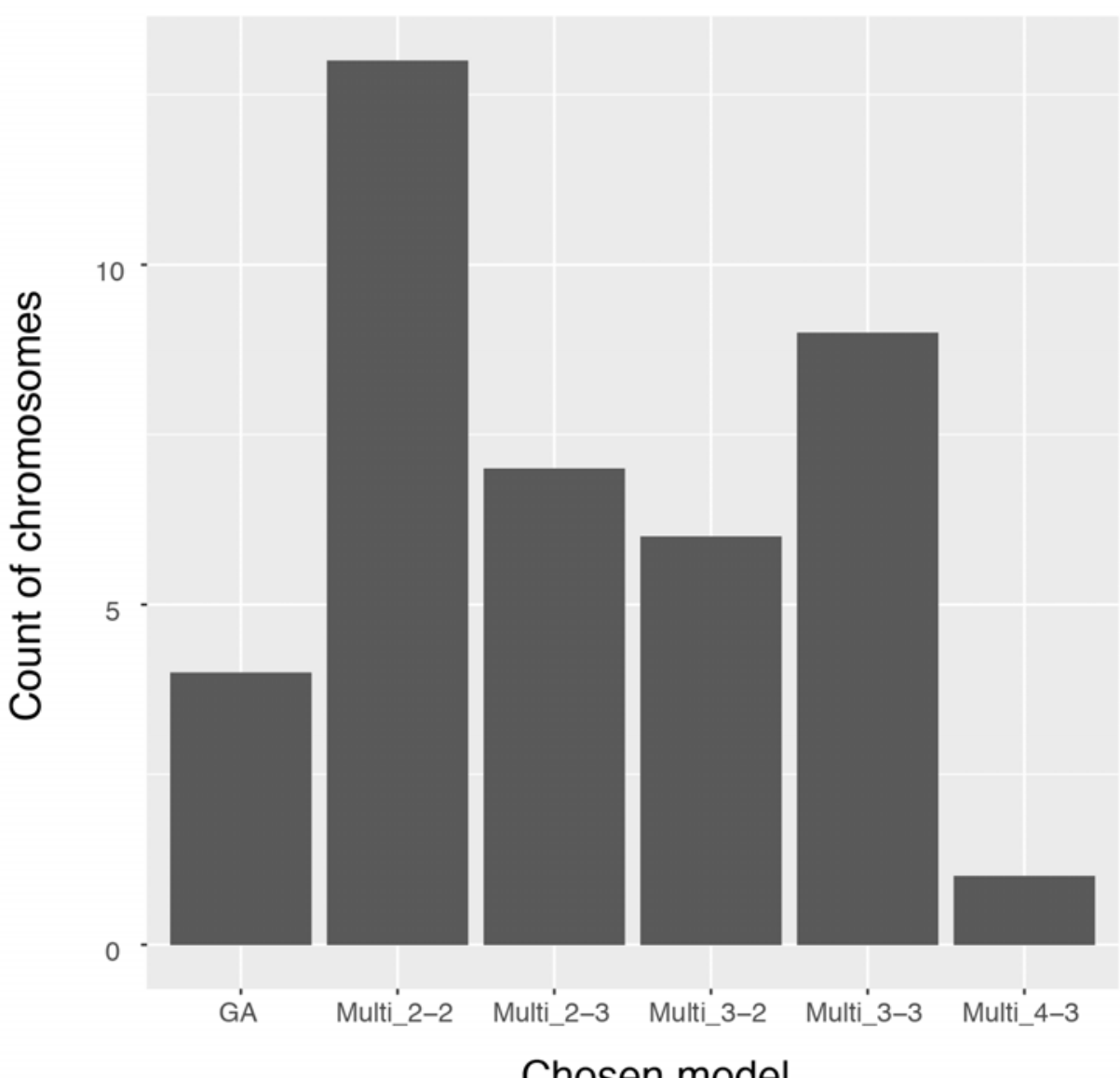


Figure S11: Admixture times inferred from ancestry block lengths in a multiple-pulse hybridization model. Time is shown in generations before the present, with the $y$-axis depicting densities based on 100 replicate datasets per chromosome, wherein heterozygous blocks were

144 randomly assigned ancestry. Note that chromosomes best fitting a single-pulse model (*) depict the inferred start time for a gradual admixture (GA) scenario in which migration rates thereafter 146 towards the present.

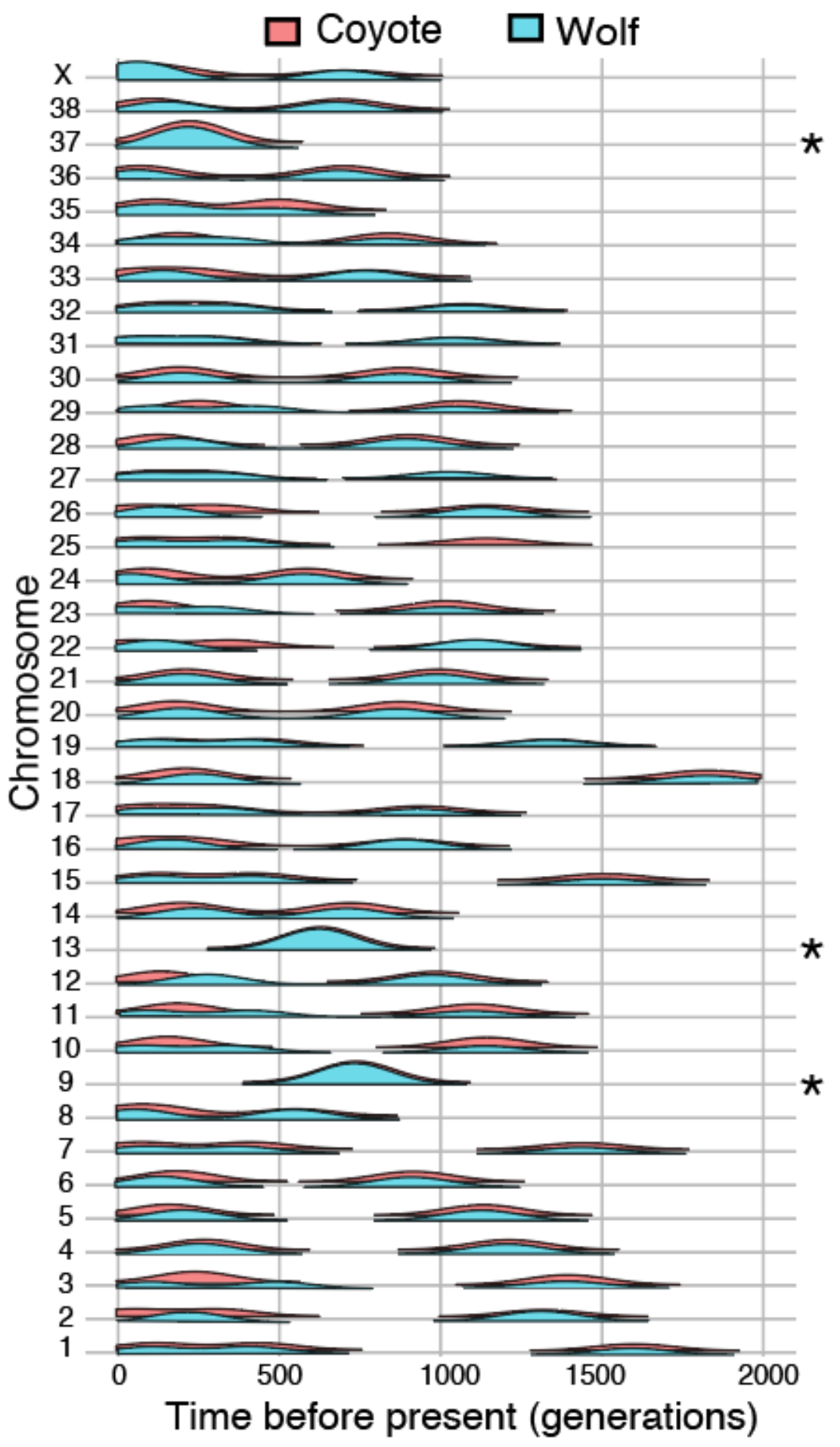


148 Figure S12: Admixture proportion for inferred admixture events inferred at different times (measured in generations before the present). The left axis (=points) show the measured

150 admixture times as a function of admixture proportions, which the right axis (=histogram) shows frequency of admixture proportions across all events.

152

2500

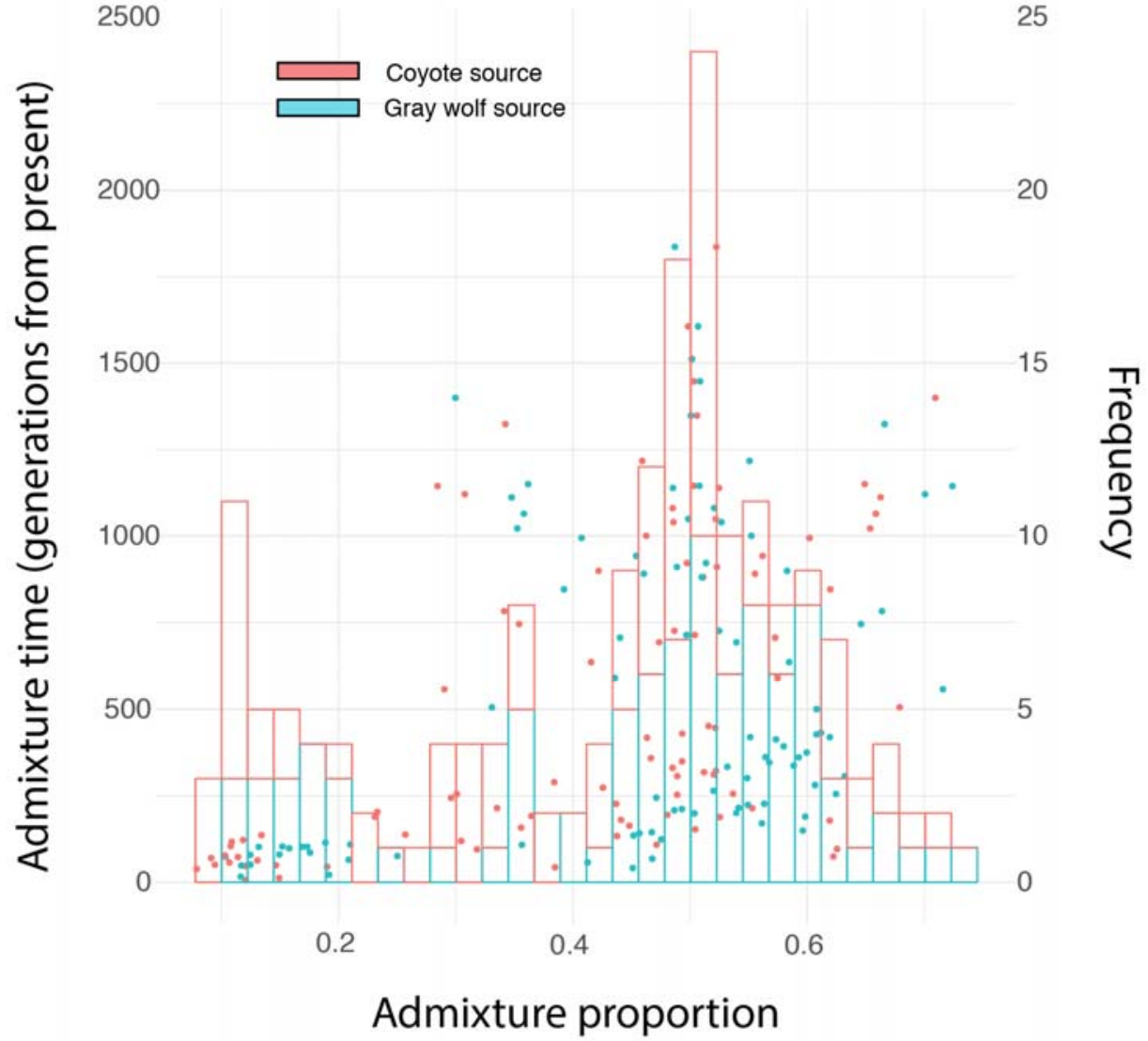

